\title{
INFLUÊNCIA DOS MEIOS DE FORMAÇÃO ÁCIDO E ALCALINO NAS CARACTERISTICAS DO PAPEL PRODUZIDO COM POLPA DE Eucalyptus spp
}

\author{
JÚLIO CÉSAR DA COSTA \\ Engenheiro Florestal
}

Orientador: Prof. Dr. LUIZ ERNESTO GEORGE BARRICHELO

Dissertação apresentada à Escola Superior de Agricultura "Luiz de Queiroz", da Universidade de São Paulo, para obtenção do título de Mestre em Ciências, Área de Concentração: Ciências Florestais.

P IR A C I C A B A

Estado de São Paulo - Brasil

Fevereiro - 1997 
Dados Internacionais de Catalogação na Publicação (CIP) DIVISĀO DE BIBLIOTECA E DOCUMENTAÇÃo - Campus "Luiz de Queiroz"/USP

\author{
Costa, Júlio César da \\ Influência dos meios de formação ácido e alcalino nas caracteristica do papel \\ produzido com polpa de Eucalyptus spp / Júlio César da Costa. - Piracicaba, 1997. \\ 69 p. : il. \\ Dissertação (mestrado) - Escola Superior de Agricultura Luiz de Queiroz, 1997. \\ Bibliografia. \\ 1. Carbonato de cálcio 2. Fibra de eucalipto 3. Papel (teenologia) I. Título.
}


INFLUÊNCIA DOS MEIOS DE FORMAÇÃO ÁCIDO E ALCALINO NAS CARACTERÍSTICAS DO PAPEL PRODUZIDO COM POLPA DE Eucalyptus spp

\author{
JÚLIO CÉSAR DA COSTA
}

Aprovada em: 03.04.1997

Comissão Julgadora:

Prof. Dr. Cláudio Angeli Sansigolo - UNESP

Prof. Dr. Mário Tomazello Filho - ESALQ/USP

Prof. Dr. Luiz Ernesto George Barrichelo - ESALQ/USP

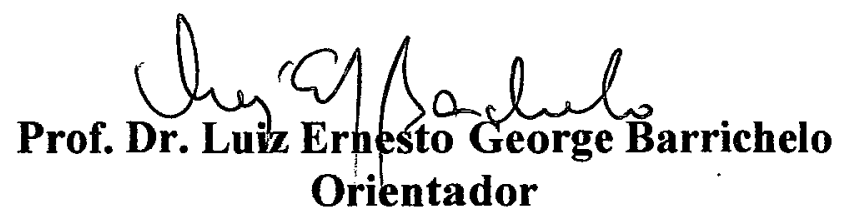




\title{
Dedicatória
}

\begin{abstract}
À minha esposa Mônica e ao meu filho Caio pela compreensão, estímulo e carinho dedicados durante toda a vida, em especial durante a execução deste trabalho.
\end{abstract}
À minha mãe Alice e à avó Antonia pela formação moral e intelectual que permitiram meu desenvolvimento pessoal e profissional. 


\section{AGRADECIMENTOS}

Aos professores e funcionários do Departamento de Ciências Florestais da ESALQ/USP pelo apoio, em especial ao Prof. Dr. Luiz Ernesto George Barrichelo, pela orientação.

Aos técnicos Alexandre dos Santos Ricobello e Fábio Sérgio de Almeida da Votorantim Celulose e Papel e Maria Regina Buch do Departamento de Ciências Florestais da ESALQ/USP, pelo auxilio analítico.

Ao Cléver Ricardo Chinaglia do Centro de Caracterização e Desenvolvimento de Materiais da UFSCAR, pelo trabalho microanalítico.

À Votorantim Celulose e Papel S/A pelo apoio e oportunidade.

À todos os amigos que incentivaram este trabalho. 


\section{SUMÁRIO}

LISTA DE FIGURAS …................................................................ Pánina

LISTA DE TABELAS …..................................................................... viii

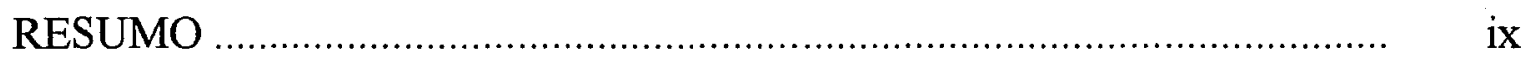

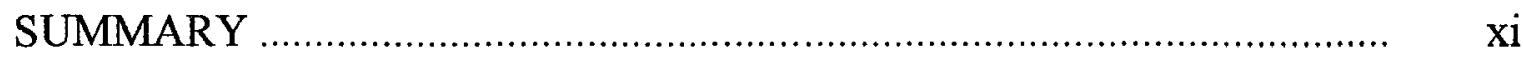

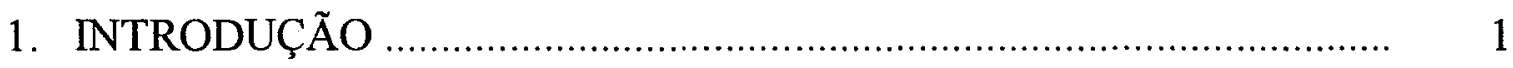

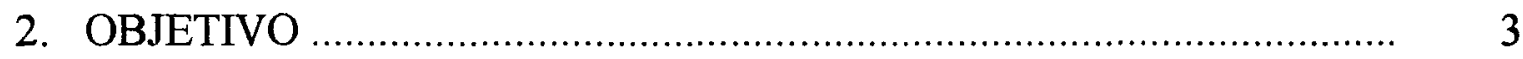

3. REVISÃO DA LITERATURA …......................................................

4. MATERIAIS E MÉTODOS _................................................................ 21

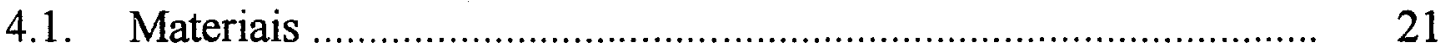

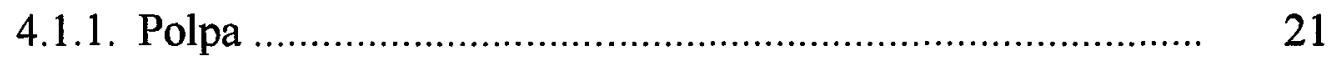

4.1.2. Produtos químicos ......................................................... 21

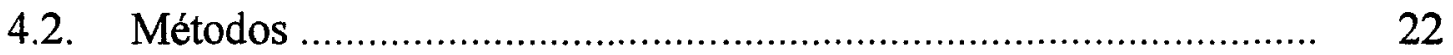

4.2.1. Fabricação de folhas manuais e análise de fibras nas condições ácida e alcalina ................................................... 22

4.2.2. Análise das propriedades das folhas manuais .................... 24

4.2.2.1. Propriedades ópticas ........................................... 24

4.2.2.2. Propriedades físico-mecânicas ............................. 24

4.2.3. Análise de papéis fabricados em escala industrial ............. 25

4.2.3.1. Propriedades ópticas ........................................... 25

4.2.3.2. Propriedades físico-mecânicas ............................. 26

4.3. Microanálise dos papéis ............................................................ 27

4.3.1. Microscopia eletrônica de varredura .................................. 27

4.3.2. Microanálise química elementar ....................................... 27 
5. DISCUSSÃO DOS RESULTADOS ………………............................. 29

5.1. Características das folhas manuais e das suspensões de fibras ..... 29

5.1.1. Características das suspensões de fibras ........................... 29

5.1.2. Características ópticas das folhas manuais ....................... 31

5.1.3. Características físico-mecânicas das folhas manuais ......... 33

5.2. Características do papel industrial .............................................. 35

5.2.1. Características ópticas ................................................... 35

5.2.2. Características físico-mecânicas ....................................... 38

5.3. Características microanalíticas dos papéis .................................... 42

5.3.1. Fotomicrografias dos papéis …………........................... 42

5.3.2. Composição química elementar das fibras no papel ........... $\quad 52$

5.4. Influência do $\mathrm{pH}$ de formação nas características do papel ........... 58

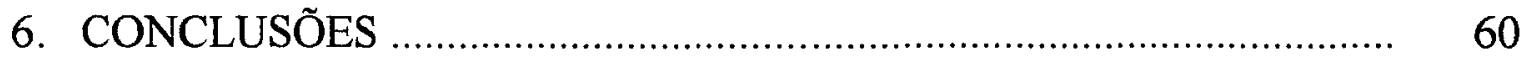

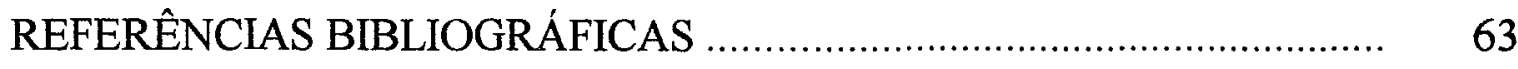

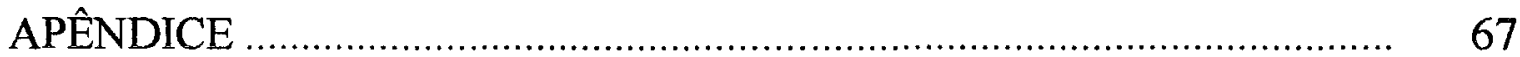




\section{LISTA DE FIGURAS}

Página

Figura 1 - Fotomicrografia de fibras tratadas em $\mathrm{pH} 5,0$ (folhas manuais)

Figura 2 - Fotomicrografia de fibras tratadas em $\mathrm{pH} 8,0$ (folhas

manuais)

Figura 3 - Fotomicrografia de fibras tratadas em $\mathrm{pH} \mathrm{5,0} \mathrm{(papel}$ industrial)

Figura 4 - Fotomicrografia de fibras tratadas em pH 8,0 (papel industrial)

Figura 5 - Fotomicrografia de fibras sem tratamento

Figura 6 - Fotomicrografia de fibras sem tratamento

Figura 7 - Fotomicrografia do papel fabricado a pH 5,0 (folhas

manuais)

Figura 8 - Fotomicrografia do papel fabricado a pH 8,0 (folhas

manuais)

Figura 9 - Microanálise da amostra original

Figura 10 - Microanálise da folha tratada em pH 5,0 (folhas manuais) ..

Figura 11 - Microanálise da folha tratada em pH 8,0 (folhas manuais) ..

Figura 12 - Microanálise da folha tratada em pH 5,0 (papel industrial) ..

Figura 13 - Microanálise da folha tratada em pH 8,0 (papel industrial) .. 


\section{LISTA DE TABELAS}

Página

Tabela 1 - Porcentagem relativa de polissacarídeos nas diferentes camadas da parede celular 13

Tabela 2 - Propriedades das suspensões de fibras

Tabela 3 - Propriedades ópticas das folhas manuais

Tabela 4 - Propriedades fisico-mecânicas das folhas manuais

Tabela 5 - Propriedades ópticas das folhas produzidas em escala

industrial

Tabela 6 - Propriedades físico-mecânicas das folhas produzidas em escala industrial 


\title{
INFLUÊNCIA DOS MEIOS DE FORMAÇÃO ÁCIDO E ALCALINO NAS CARACTERÍSTICAS DO PAPEL PRODUZIDO COM POLPA DE Eucalyptus spp
}

\author{
Autor: JÚLIO CÉSAR DA COSTA \\ Orientador: PROF.DR. LUIZ ERNESTO GEORGE BARRICHELO
}

Resumo

O estudo da influência dos meios de formação ácido e alcalino, nas características do papel produzido com polpa sulfato branqueada de eucalipto, procura as possíveis evidências de diferenciação do comportamento das fibras nestes meios.

Isto foi estudado durante a formação em meio ácido $(\mathrm{pH} 5,0)$ e meio alcalino ( $\mathrm{pH} \mathrm{8,0),} \mathrm{promovidos} \mathrm{por} \mathrm{sulfato} \mathrm{de} \mathrm{alumínio} \mathrm{e} \mathrm{hidróxido} \mathrm{de} \mathrm{cálcio.}$

Foram analisados diâmetro externo, diâmetro do lúmen, espessura da parede, fração parede e coeficiente de flexibilidade das fibras e as características dos papéis produzidos nas mesmas condições. 
As análises dos dados mostram que o diâmetro do lúmen decresce com o tratamento alcalino em comparação ao tratamento ácido, resultando em decréscimo do coeficiente de flexibilidade e aumento da fração parede.

As fibras tratadas em meio alcalino produzem um papel com maior volume específico devido às suas transformações anatômicas, apresentando menor acomodação e portanto, maiores volumes de vazios entre si.

O papel alcalino apresentou resistências mecânicas levemente inferiores, devido às menores ligações fibra a fibra, confirmado pelos maiores coeficiente de espalhamento de luz e opacidade.

O papel produzido na condição ácida apresenta menor alvura, provavelmente pela hidrólise ácida das hemiceluloses, causando amarelecimento.

Papéis com cargas minerais como o caulim e o carbonato de cálcio exibem as mesmas tendências nas condições ácida e alcalina. O nível de carga pode aumentar ou diminuir cada efeito.

Estas características se mantém após a secagem do papel. 
THE INFLUENCE OF ACID AND ALKALINE FORMATION ENVIRONMENT ON THE CHARACTERISTICS OF PAPER WITH

Eucalyptus spp PULP

\author{
Author: JÚLIO CÉSAR DA COSTA \\ Adviser: PROF.DR. LUIZ ERNESTO GEORGE BARRICHELO
}

SUMMARY

The study of the influence of $\mathrm{pH}$ on paper characteristics from Eucalyptus spp bleached kraft pulp searches the possible differing evidences in fiber behavior in acid and alkaline environment.

It was studied during formation in $\mathrm{pH} 5,0$ and $\mathrm{pH} 8,0$, provided by aluminium sulphate and calcium hidroxide. The external diameter, lumen diameter and wall thickness of the fibers, the wall fraction and flexibility coeficcient rates were analyzed, togheter with the papers characteristics under the same conditions. 
The data analized shows the lumen diameter decreasing with the alkaline treatment, in comparation to the acid treatment, resulting in decreased flexibility coefficient, increased wall fraction and decreased lumen volume in the fibers.

The alkaline paper shows less compacted structure, with more voids and more bulk and slightly lower mechanical strenght, due to less fiber to fiber bridging, confirmed by light scattering coefficient and opacity. The acid condition provides lower brightness, probably because of hydrolysis of the acid pulp, causing yellowing.

Papers with mineral fillers, kaolim and calcium carbonate, in acid or alkaline conditions, exhibit the same tendency. The filler level can increase or decrease each effect.

The fiber treated under alkaline medium is more bulky and has more voids between the fibers due to a change in fiber anatomy consisting of less fiber flexibility and less fiber to fiber accommodation. These paper characteristics remain the same while wet and after drying. 


\section{INTRODUÇÃO}

Desde os primórdios da indústria papeleira brasileira o papel vem sendo produzido em meio ácido, conseqüente do uso do sulfato de alumínio em solução.

Este composto é utilizado em conjunto com a cola de breu para formar o resinato de alumínio, responsável pela colagem das fibras no papel, conferindo resistência à absorção de água. Este conjunto de fatores são denominados como colagem ácida.

Com a elevação dos custos da polpa celulósica, iniciou-se a substituição de fibras por cargas minerais, como o caulim.

Esta substituição até níveis de $15 \%$ é aceitável pois, não alteram as resistências físico-mecânicas do papel de modo significativo, provocando uma redução de custos de produção do mesmo.

O desenvolvimento de tecnologias para a utilização de carbonato de cálcio com melhores características ópticas e menor custo, comparado ao caulim, modificou as condições de processo de fabricação de papel, pois em meio ácido com a presença de sulfato de alumínio este reage e se dissocia formando espuma (bolhas de gás carbônico) e o sulfato de cálcio solúvel formado é retirado na parte úmida da máquina de papel durante a drenagem da folha. 
Portanto foram substituídos o sulfato de alumínio e a cola de breu por agentes de colagem compatíveis com o meio alcalino que o carbonato de cálcio promove, como por exemplo cola de breu em emulsão, dímero de alquil ceteno (cola AKD) e anidrido alquenil succínico (cola ASA). Esta nova tecnologia de fabricação de papel é denominada colagem alcalina.

Papéis com colagem alcalina apresentam características fisico-mecânicas e ópticas diferentes do papel com colagem ácida, atribuídas às características das cargas utilizadas, porém não se conhece ainda a contribuição do comportamento das fibras nestes meios.

A produção de papel alcalino no Brasil iniciou-se há muitos anos em pequenas máquinas que fabricavam papéis especiais. Em 1995 grandes fábricas iniciaram a produção de papéis alcalinos para imprimir e escrever.

Sendo o Brasil um dos únicos países do mundo a fabricar papel com $100 \%$ de fibra de eucalipto e tendo iniciado a produção de papéis alcalinos, faz-se oportuno o estudo comparativo do comportamento de suas fibras em meios alcalino e ácido e seus reflexos nas características do papel para compreensão das possíveis mudanças ocorridas. 


\section{OBJETIVO}

Este estudo visa analisar a influência dos meios ácido e

alcalino no comportamento das fibras de eucalipto e seus reflexos nas características do papel. 


\section{REVISÃO DA LITERATURA}

As principais características do papel influenciadas pela colagem alcalina em relação à colagem ácida são: espessura, densidade aparente, volume específico aparente, resistência ao ar, opacidade, alvura, longevidade, porosidade e rigidez. Porém, para um bom entendimento deveremos estudar o comportamento do material fibroso submetido aos meios ácido e alcalino.

A polpa obtida da madeira tem suas características influenciadas pela sua origem, espécie e processo de obtenção, entre outros. Todas as madeiras apresentam células de parênquima, porém as coníferas, além desta, apresenta predominantemente traqueídeos com poucas fibras libriformes e sem vasos, enquanto as folhosas, apresentam poucos traqueídeos e muitas fibras libriformes especializadas e vasos, devido a sua grande necessidade de rapidez no transporte de água durante a formação da copa, no verão, em curto espaço de tempo. Traqueídeos e fibras libriformes apresentam grandes variações dimensionais entre si, gerando grande número de trabalhos acerca de comprimento, diâmetro e espessura de parede por serem considerados fundamentais em tecnologia de celulose e papel. 
Os fatores que regem estas variações entre e dentro de árvores são: espécie, idade da árvore, altura do tronco, condições de crescimento e proporção de lenho primaveril e outonal.

RYDHOM (1965), explica que na divisão das células do câmbio é formada a lamela média entre as células irmãs.

As células do xilema desenvolvem uma parede celular (constituída de celulose principalmente) em volta da cavidade central, o lúme. Os lúmes de elementos estruturais adjacentes são separados por duas paredes celulares intercaladas de lamela média.

Estas estruturas entre lúmes apresentam perfurações permitindo a passagem de água e seiva no vegetal vivo e assumem grande importância para a penetração do licor de cozimento na polpação. Com o envelhecimento da parte interna do tronco, estas células não necessitam transportar seiva, então diferentes tipos de extrativos, com propriedades fungicidas são depositados, diferenciando a cor desta parte interna, chamada a partir disso de cerne.

A densidade da substância madeira (desconsiderados os vazios das fibras) é cerca de $1,53 \mathrm{~g} / \mathrm{cm}^{3}$ e varia muito pouco com a espécie, crescimento e composição química. Porém a densidade da madeira varia bastante 
de 0,04 (Aeschynomene) a $1,42 \mathrm{~g} / \mathrm{cm}^{3}$ (Krugiodendron). As espécies comerciais para polpação apresentam densidades de 0,3 a $0,6 \mathrm{~g} / \mathrm{cm}^{3}$.

O máximo de água que a madeira retém é dado pela sua porosidade, sendo que a madeira verde do alburno retém água saturada em todas as suas cavidades e o cerne tem estas cavidades ocupadas por ar.

A madeira é composta pelos elementos carbono, hidrogênio e oxigênio, desprezando-se nitrogênio $(0,1 \%)$ e cinzas $(0,3 \%)$ na proporção de $50 \%$ de carbono, $6 \%$ de hidrogênio e $44 \%$ de oxigênio, com mínimas variações entre espécies de folhosas e coníferas. Porém a diferenciação química se dá nas substâncias componentes como ácidos, álcalis, oxidantes e solventes orgânicos, variando em quantidade e proporção com as espécies, dentro da espécie, dentro da árvore e dentro das paredes celulares. Para se ordenar sistematicamente a composição da madeira, os componentes são classificados segundo a metodologia analítica disponível, pois a natureza exata dos componentes ainda é desconhecida em muitos casos.

A celulose, presente em todos os vegetais, é definida como um carboidrato constituído de glicose e isômeros do amido, podendo ser identificada como celulose Cross \& Bevan ou Alfa-celulose. Outros elementos similares em composição à celulose ocorrem como as hemiceluloses, que apresentam comportamento diferente em meio alcalino ou ácido. 
O termo holocelulose resume a totalidade de carboidratos. A celulose é um polissacarídeo de longa cadeia molecular, insolúvel em água ou ácidos e álcalis diluídos, à temperatura ambiente, constituída de anidro glicose com ligações beta 1-4 glucosídicas e de estrutura bem ordenada.

As hemiceluloses, são polissacarídeos como ácido urônico, etc. As ligninas são polímeros aromáticos de quatro ou mais monômeros de fenil propano por molécula. Os extrativos são compostos de cadeia molecular pequena, extraíveis em água ou solventes orgânicos, não classificáveis como hemiceluloses ou lignina.

A massa fibrosa da madeira é denominada polpa (também referida como celulose). O termo pentosanas exprime unidades de anidroxilose e anidroarabinose em contraste com hexosanas, ou monômeros de hexoses.

CLARK (1982) relata as interações de polpa e água, explicando que a água apresenta principalmente ligações covalentes dada a distribuição assimétrica de elétrons devido à diferença de atração dos pares de elétrons do hidrogênio e oxigênio (ou polaridade), sendo que os lados opostos da molécula não são simetricamente carregados.

Um grupo ionizado tem deficiência ou excesso de elétrons no último orbital sendo chamados de radical, íons ou íon complexo. 
Os grupos hidroxílicos na superficie da celulose tem grande afinidade com água. As moléculas de água tem áreas positivas e negativas, ou seja, são dipolares. Estas diferenças de carga fazem com que moléculas de água atraiam outras formando extensos agregados $\left(\mathrm{H}_{2} \mathrm{O}\right)_{n}$, com o aumento da temperatura esta extensão diminui, sendo estes agregados desfeitos por completo com a vaporização. Estas ligações são chamadas de pontes de hidrogênio.

As moléculas de um líquido são atraídas em todas as direções pelas moléculas vizinhas. Quando uma molécula está submersa, ela está balanceada, sem energia livre; quando na superfície, ela tem uma parte de suas forças desbalanceadas. Estas forças juntadas com as das moléculas vizinhas criam a tensão de superfície.

Quando a superficie de um líquido é aumentada, é necessário energia para separar as moléculas adjacentes e aflorar as moléculas internas. Esta tensão faz com que os líquidos tendam a ter o mínimo de área exposta, porisso a gota tende ao formato esférico.

Quando um tubo de vidro limpo, com diâmetro interno ínfimo é imerso perpendicularmente em água, observa-se a formação de menisco paralelo à superfície da água, sendo que a tensão superficial da água eleva o menisco pelo tubo. 
Quanto menor o diâmetro do tubo, maior será a pressão exercida para elevar a água em seu interior. Portanto em poros muito pequenos ou fissuras estreitas de elementos anatômicos da polpa, maior será a pressão exercida para reter água líquida. Por isso, a penetração da água nas fibras deve ser chamada embebição.

CLARK (1982) conclui ainda que a pressão ou sucção aplicada no sistema água-polpa tem pouca interferência na indução à penetração da água na parede da fibra frente ao enorme efeito de tensão superficial que a faz penetrar no interior da fibra.

Os grupos hidroxílicos da superfície da celulose tem grande afinidade com a água. Uma celulose absolutamente seca retira parte da água de um poderoso dissecante, o pentóxido de fósforo que havia retido um pouco de vapor d'água. O espectro infravermelho de celuloses absolutamente seca e úmida confirmou a retenção de água por pontes de hidrogênio.

As moléculas na primeira camada de água retida pela celulose são orientadas e empacotadas, apresentando $2,5 \mathrm{~g} / \mathrm{cm}^{3}$. Isto fundamenta o conceito da necessidade de temperaturas maiores de $150^{\circ} \mathrm{C}$ para retirar toda a água adsorvida.

A primeira camada de água retida pela celulose apresenta grupos hidroxílicos, que por sua vez retém a segunda camada de água e esta da 
mesma forma atrai a terceira e assim sucessivamente, sendo que a densidade e organização vão decrescendo. Em condições ambientes são adsorvidas aproximadamente sete camadas.

Faz-se necessário ressaltar que o processo recém descrito é denominado adsorsão, sendo que o termo absorção encerra toda a água e vapor presente num sólido.

O algodão apresenta maiores moléculas de celulose e é muito menos higroscópico que uma polpa de alto rendimento com maiores índices de açúcares, hemiceluloses e outros componentes hidrofilicos.

GALLAY (1962) estuda profundamente as características desta relação afirmando que a molécula de celulose é uma macromolécula de cadeia longa e apresenta características que não são mostradas pelos monômeros ou moléculas de cadeia mais curta. Estas características são devidas a um enorme comprimento de cadeia em relação à pequena seção transversal.

Um sistema de macromoléculas pode variar de completamente amorfo a altamente cristalino, dependendo da estrutura química do material e sua formação.

O sistema celulose-água é composto por polímero de cadeia longa altamente polar e um líquido altamente polar. A umidade retida pela 
celulose é regida pela sua cristalinidade, sendo que a celulose amorfa aumenta a acessibilidade da água à cadeia.

A celulose seca é extremamente higroscópica, retendo água avidamente. A absorção aumenta com a umidade relativa sendo da ordem de 10 a $12 \%$ sobre a massa em condições ambientes, de $30 \%$ em atmosfera saturada e 200 à 300\% em água líquida.

A absorção se processa rapidamente nas regiões amorfas e não ocorre este processo nas regiões cristalinas, que não incham, podendo se dar em três etapas: adsorsão, embebição e ação capilar.

A fibra de celulose é considerada composta de macromoléculas que são arranjadas em regiões com maior ou menor ordenamento. Nas regiões de maior cristalinidade as moléculas ou seções de moléculas são fixadas por pontes de hidrogênio entre as hidroxilas. Nas regiões amorfas existe grande proporção de hidroxilas livres o que permite uma grande absorção de água. Quando isso acontece existe separação de moléculas ou segmentos de moléculas, sendo muito influenciada pelo calor. As pontes de hidrogênio são assim desfeitas entre hidroxilas da celulose e novos centros de absorção ficam liberados, retendo assim mais água.

A absorção portanto, promove o inchamento da fibra, causando profundos efeitos nas suas propriedades físicas. 
Uma abordagem a nível de processamento é feita por LYNE e ASPLER (1982), dizendo que o aumento dos poros formados pelas fibras na forma de folha são responsáveis diretamente pela maior absorção de água.

D'ALMEIDA (1988) e FENGEL (1984), explicam que os grupos hidroxílicos da molécula de celulose são capazes de formar dois tipos de pontes de hidrogênio dependendo de sua localização na unidade de glucose. As pontes de hidrogênio entre grupos hidroxílicos de unidades de glucose adjacentes na mesma molécula de celulose (ligações intramoleculares) conferem rigidez ’as cadeias unitárias. As pontes de hidrogênio entre grupos hidroxílicos de moléculas de celulose adjacentes (ligações intermoleculares) são responsáveis pelo alinhamento da molécula formando as microfibrilas que formam as fibrilas que por sua vez se ordenam formando então as camadas da parede celular.

O látice cristalino é a estrutura onde as moléculas de celulose estão dispostas na forma diagonal com determinado ângulo e espaços (celulose I). Os tratamentos químicos alteram o látice cristalino da celulose. O tratamento mais conhecido é a mercerização da celulose. O tratamento com $\mathrm{NaOH}$ incha o látice e é função da concentração de $\mathrm{NaOH}$ e temperatura. Removendo o $\mathrm{NaOH}$ em excesso é formado um novo látice a Na-celulose I (ou alcali-celulose I). A álcali celulose apresenta maiores distâncias entre as moléculas de celulose. Os grupos $\mathrm{OH}$ da celulose são transformados em grupos $\mathrm{O} \mathrm{Na}$ e as dimensões da 
molécula de celulose aumentam. Lavando-se intensivamente a polpa com água remove-se os íons $\mathrm{Na}$ dos grupos hidroxílicos e forma-se outro látice a celulose II. MCGINNIS e SHAFIZADEH (1980) citando MEIER (1961) apresentam uma tabela contendo a composição química dos elementos estruturais da madeira da qual se destacou a tabela 1.

Tabela 1 - Porcentagem relativa de polissacarídeos nas diferentes camadas da parede celular

\begin{tabular}{|c|c|c|c|c|c|}
\cline { 2 - 6 } \multicolumn{2}{c|}{} & $\begin{array}{c}\text { lamela } \\
\text { média } \\
\text { parede } \\
\text { primária }\end{array}$ & $S 1$ & $\begin{array}{c}\text { S2 } \\
\text { externa }\end{array}$ & $\begin{array}{c}\text { S2 e S3 } \\
\text { interna }\end{array}$ \\
\hline \multirow{2}{*}{$\begin{array}{c}\text { Pinus sylvestris } \\
\text { (conifera) }\end{array}$} & celulose, \% & 35,5 & 61,5 & 66,5 & 47,5 \\
\cline { 2 - 7 } & hemiceluloses, \% & 64,5 & 38,4 & 33,6 & 52,2 \\
\hline \multirow{2}{*}{$\begin{array}{c}\text { Betula verrucosa } \\
\text { (folhosa) }\end{array}$} & celulose, \% & 41,4 & 49,8 & 48,0 & 60,0 \\
\cline { 2 - 7 } & hemiceluloses, \% & 58,6 & 50,0 & 52,0 & 40,2 \\
\hline
\end{tabular}


CLARK (1982) define a opacidade como uma importante propriedade de papéis de imprimir e escrever, principalmente quando são utilizados os dois lados da folha. Para se diminuir os custos de material postal e diminuir a espessura de livros como a bíblia é necessário o uso de papel de baixa gramatura e o mais fino possível, sem deixar o papel transparecer a impressão ou escrita do lado oposto. Partículas minerais adicionadas à polpa têm maior efeito em opacidade que as fibras sozinhas.

O coeficiente de espalhamento de luz (C.E.L.) indica a extensão da superfície da fibra sem contato entre si, porém sua utilização deve ser restrita às propriedades ópticas, pois as áreas de contato ótico são muito diferentes das áreas de contato fibrilar e molecular. C.E.L. envolve a medição da reflectância $R_{0}$ de uma folha de papel sobre um suporte preto e da reflectância $R_{\infty}$ quando a folha é suportada por outras folhas idênticas a ela em número suficiente para que a pilha de folhas formada seja opaca.

Pelo método TAPPI T425 o C.E.L. poderá ser obtido diretamente. A gramatura da amostra analisada deve ser determinada, porém as diferenças de gramatura entre amostras condicionadas ou secas em estufa são desprezíveis. O volume específico aparente pode indicar a compactabilidade à úmido das fibras, C.E.L. a área relativa de contato entre elementos e a drenagem da polpa na máquina de papel. 
DAUGHTY citado por CLARK (1982) estabeleceu o termo fração sólida, que equivale ao volume específico de celulose cristalina $(0,64$ $\mathrm{cm}^{3} / \mathrm{g}$ ) dividido pelo volume específico aparente da folha de papel em $\mathrm{cm}^{3} / \mathrm{g}$. A fração sólida é a medida das ligações das superfícies internas e externas das fibras. O volume específico aparente ou o seu inverso, a densidade da folha, indicam a área relativa da superfície externa colada das fibras na folha de papel.

Na prática, quando o processo de refino é extremo como para papéis glassine, o valor de volume específico aparente e densidade aparente são próximos de 1 , com toda a superfície externa da fibra colada. Por isso é melhor e mais compreensivel o uso do volume específico aparente ou densidade aparente no lugar da fração sólida. Portanto, uma folha com densidade $0,5 \mathrm{~g} / \mathrm{cm}^{3}$ ( ou volume específico aparente $=2 \mathrm{~cm}^{3} / \mathrm{g}$ ) tem cerca de metade da superficie externa das fibras coladas entre si.

Estudos encontrados na literatura tratam do efeito do $\mathrm{pH}$ sobre o refino, porém não encontrou-se referência de sua ação na formação do papel.

GERTEISE e LAUFMANN (1987) evidenciam que a colagem alcalina melhora as resistências do papel e aumenta sua brancura e opacidade pela presença do carbonato de cálcio, explicando que em condições alcalinas, as fibras são mais rapidamente refinadas e fibrilam mais durante o 
refino, criando melhores condições para a formação das pontes de hidrogênio e tendo como resultado, maior resistência do papel. Entretanto, o uso de sulfato de alumínio, um aditivo barato e versátil para fabricação de papéis ácidos, causa distúrbios nestas ligações reduzindo a resistência do papel com colagem ácida.

Os aditivos para colagem do papel em meio alcalino necessitaram de desenvolvimento, pois os aditivos naturais não promoviam a colagem neste meio. RIEBELING (1990) descreve as colas sintéticas disponíveis, a cola AKD como uma cera sólida e a cola ASA como um líquido semelhante ao óleo diesel, ambas insolúveis em água, sendo necessário que sejam emulsificadas para uso pois reagem com a água resultando em dialquil cetona e ácido succínico. Como colóide protetor é utilizado o amido catiônico na emulsificação das colas para evitar a reação com água. Estas colas são reativas e formam ligações covalentes com as fibras.

MARTON (1991) compara métodos para colagem do papel apontando a emulsão ASA como fortemente reativa com as hidroxilas da celulose e água em relação à cola de breu em emulsão e ainda à emulsão $\mathrm{AKD}$, consequentemente sua vida útil é menor (máximo duas horas). A reação de esterificação da emulsão ASA com a celulose promove uma colagem total do papel antes do mesmo sair da máquina produtora. 
GILL (1990) relata o rápido crescimento do processo alcalino para fabricação de papel, substituindo o processo ácido nos E.U.A., desde 1986 devido a oferta de carbonato de cálcio precipitado de alta qualidade a baixo custo, provenientes de plantas de produção de carbonato de cálcio em fábricas de polpa e papel integradas. Nestas plantas se consome o $\mathrm{CO}_{2}$ do forno de cal e também cal de alta reatividade para produção de carbonato de cálcio precipitado que pode ter diferentes formatos e tamanhos modulados pelo controle da reação de carbonatação. Relata ainda que as propriedades do papel são muito influenciadas pelo tamanho e formato da partícula da carga.

As partículas de carbonato de cálcio precipitado no formato escalenoédrico e no formato romboédrico $(0,7$ a $3,0 \mu \mathrm{m})$ aumentam a opacidade do papel quando comparados a caulim e carbonato de cálcio natural. A alvura do papel também é beneficiada pelo uso de carbonato de cálcio natural e precipitado (alvura 75,5 a $87,5 \%$ TAPPI) em relação ao caulim (83\% TAPPI) nas mesmas condições de fabricação do papel e níveis de carga.

KAMITI e VAN DE VEN (1994) apontam formas disponíveis do carbonato de cálcio natural: giz e pedra calcárea, e sintética: precipitado. Papéis com carbonato de cálcio natural geralmente apresentam menor brancura, opacidade e volume específico aparente quando comparados com papéis com carbonato de cálcio sintético, pois a forma natural apresenta 
impurezas e tem partículas maiores, enquanto a sintética é relativamente pura podendo ser fabricadas de duas formas: cálcitica e aragonítica.

HAGEMEYER e WELCH (1981) concluem que o aumento da brancura e opacidade do papel é inversamente proporcional ao tamanho das partículas sendo que o estudo em questão chegou ao limite de $90 \%$ da população de partículas de carbonato de cálcio natural com o diâmetro de $2 \mu \mathrm{m}$, sendo seu tamanho médio de $0,75 \mu \mathrm{m}$.

FAIRCHILD (1992) estudou a influência das partículas de carbonato de cálcio precipitado com diferentes morfologias e em dosagens crescentes ( 15 a $25 \%$ ) para substituição de fibras, concluindo que misturas de morfologias escalenoédricas e prismáticas são necessárias para que mesmo com o aumento de carga mineral mantenha-se a resistência, rigidez e características ópticas do papel.

KAMITI e VAN DE VEN (1994) concluem que a deposição de $\mathrm{CaCO}_{3}$ sobre as fibras dependem da atração eletrostática ou repulsão entre este e as fibras através de forças de Van der Waals.

GILL (1990) observa que o volume específico de papéis com $16 \%$ de carga de carbonato de cálcio demonstra diferentes valores conforme a morfologia utilizada, sendo que a forma escalenoédrica a que confere maiores valores. 
PASSARETTI (1991) conclue que adições progressivas de carbonato de cálcio ( 8 a $24 \%$ ) aumentam a opacidade e brancura do papel, sendo a forma romboédrica de $0,3 \mu \mathrm{m}$ a de maior opacidade.

SANDERSON (1990) aponta o volume específico aparente, opacidade, alvura e rigidez como as principais vantagens do papel alcalino sobre o papel ácido na impressão offset litográfica, pois os maiores volume específico aparente e rigidez são benéficos para a soltura da folha impressa da blanqueta de impressão, a alvura aumenta o contraste e define melhor o contorno dando maior impacto visual aliado a maior opacidade que evita a transferência da imagem impressa ao lado oposto da folha.

A longevidade dos papéis é uma constante preocupação de bibliotecários e arquivistas. PAISTE (1981) evidencia a maior longevidade dos papéis alcalinos em relação aos ácidos pela presença de carbonato de cálcio que inibe a hidrólise ácida da celulose, pois neutraliza os ácidos formados pela poluição, não degenerando as resistências do papel.

WATERHOUSE e BARRET (1991) estudando papéis fabricados entre os anos 1400 e 1711 , notaram que os papéis alcalinos tinham maior resistência que os ácidos, e ainda melhor estado de conservação.

SCLAWY e WLLIAMS (1981) também evidenciam a colagem alcalina como caminho para evitar a deterioração de publicações, desde 
que o carbonato de cálcio seja maior que $3 \%$ sobre o peso seco do papel, conferindo assim longevidade de centenas de anos contra o máximo de 150 anos de papéis com colagem ácida. 


\section{MATERIAIS E MÉTODOS}

\subsection{Materiais}

\subsubsection{Polpa}

Foi utilizada polpa sulfato branqueada industrial produzida pela Cia. Votorantim de Celulose e Papel Ltda, Brasil, constituída de $70 \%$ Eucalyptus grandis, 20\% Eucalyptus saligna e 10\% Eucalyptus urophylla, cuja caracterização encontra-se no anexo I.

\subsubsection{Produtos químicos}

Amostras de polpas a $0,5 \%$ de consistência foram submetidas a dois tratamentos, (i) com sulfato de alumínio isento de ferro para acidificação até $\mathrm{pH} 5,0$ e (ii) hidróxido de cálcio para alcalinização até $\mathrm{pH} 8,0$. Estes produtos são os responsáveis pela promoção do $\mathrm{pH}$ do meio de formação ácido e alcalino na fabricação industrial de papéis. O hidróxido de cálcio representa o produto de 
solubilização do carbonato de cálcio normalmente empregado como carga na colagem alcalina.

\subsection{Métodos}

\subsubsection{Fabricação de folhas manuais e análise de fibras nas condições ácida e alcalina.}

$\mathrm{Na}$ confecção de folhas manuais não foram utilizadas cargas minerais para se estudar exclusivamente a influência das fibras em condições ácida e alcalina nas características do papel.

Foi utilizada polpa refinada a $\mathrm{pH} 8,0$ (controlado com hidróxido de sódio) e apresentando drenabilidade de $38^{\circ} \mathrm{SR}$ e $4 \%$ de consistência.

Esta massa foi diluída até consistência $0,5 \%$ e foram preparados 2 tratamentos a $\mathrm{pH} 5,0$ e $\mathrm{pH} 8,0$ (repetidos 3 vezes em ordem aleatória entre tratamentos para formação de folhas, sendo 25 folhas por repetição e 5 vezes em ordem aleatória para medição das dimensões transversais da fibra) e ainda mantida uma amostra testemunha a $\mathrm{pH}$ original.

$\mathrm{O}$ pH foi ajustado pela adição de sulfato de alumínio (acidificação) e hidróxido de cálcio (alcalinização) conforme necessário a cada tratamento. 
Aguardou-se uma hora para condicionamento sob agitação e pH constantes, quando mediu-se as dimensões transversais das fibras. Estas dimensões foram obtidas através de lâminas com fibras coloridas com safranina levadas ao microscópio ótico e com auxílio de ocular micrométrica foram medidos os diâmetros interno (DL - diâmetro do lúme) e externo ( $\mathrm{L}$ - diâmetro da fibra) na parte média do comprimento. A partir destas medições foram calculadas a espessura da parede celular, fração parede e coeficiente de flexibilidade utilizando-se as seguintes fórmulas:

$\mathrm{E}($ Espessura da parede $)=\frac{L-D L}{2}$

$\mathrm{CF}($ Coeficiente de flexibilidade $)=\frac{D L}{L} \times 100$ $\mathrm{FP}($ Fração parede $)=\frac{2 E}{L} \times 100$

Foram medidas 25 fibras em cada repetição dos tratamentos e formadas folhas manuais conforme norma Tappi T205 sp-95, na gramatura 85 $\mathrm{g} / \mathrm{m}^{2}$, acondicionadas conforme norma Tappi T402 om-93. 
4.2.2. Análise das propriedades das folhas manuais.

\subsubsection{Propriedades ópticas.}

Foram analisadas as seguintes propriedades:

- Coeficiente de espalhamento de luz (C.E.L.) - norma Tappi T220 sp-96.

- Opacidade - norma Tappi T425 om-91.

- Alvura - norma Tappi T452 om-92.

\subsubsection{Propriedades físico-mecânicas.}

Foram determinadas as características:

- Gramatura, espessura, volume específico aparente, alongamento, resistência à tração, resistência ao arrebentamento e resistência ao rasgo - Norma Tappi T220 sp-96.

- Resistência ao ar Gurley - Norma Tappi T460 om-96.

- $\quad$ Rigidez - Norma Tappi T489 om-92. 


\subsubsection{Análise de papéis fabricados em escala industrial.}

Obteve-se dados de análise de papéis offset $75 \mathrm{~g} / \mathrm{m}^{2}$ de uma mesma máquina de papel de alta velocidade, nas condições ácida e alcalina, fabricados com o mesmo material fibroso, ou seja polpa sulfato branqueada de eucalipto, sendo a versão ácida composta da carga caulim de $11 \mu \mathrm{m}$ de diâmetro médio, cola de breu, amido catiônico e sulfato de alumínio (formadas a pH 5,0).

$\mathrm{Na}$ versão alcalina foi utilizada carga de carbonato de cálcio precipitado com partícula escalenoédrica de $1,9 \mu \mathrm{m}$ de diâmetro médio, cola ASA e amido catiônico (formadas a pH 8,0).

Os papéis ácidos e alcalinos foram submetidos às mesmas condições mecânicas de máquina e de velocidade, sendo divididos em duas classes de teor de carga, $15 \%$ (14 a $16 \%)$ e $17 \%(16,1$ a $18 \%)$. e coletados o mesmo número de observações para cada variável, conforme métodos e números de observações (para cada tipo) expostas a seguir.

\subsubsection{Propriedades ópticas.}

Foram determinadas as propriedades: 
- Opacidade - norma Tappi T425 om-91 - 479 amostras.

- Alvura - norma Tappi T452 om-92 ( Com utilização de filtro de raios ultra-violeta para eliminação de possíveis efeitos de variação de alvejamento ótico) - 558 amostras.

\subsubsection{Propriedades físico-mecânicas.}

Foram analisados:

- Espessura - Norma Tappi T 411 om-89 - 490 amostras.

- Volume específico aparente - Norma Tappi T220 sp-96 - 489 amostras.

- Alongamento transversal - Norma Tappi 494 om-88 - 78 amostras.

- Alongamento longitudinal - Norma Tappi 494 om-88 - 78amostras.

- Resistência à tração transversal - Norma Tappi T494 om-88 - 76 amostras.

- Resistência à tração longitudinal - Norma Tappi T494 om-88 - 76 amostras.

- Resistência ao arrebentamento - Norma Tappi T403 om-91 - 82 amostras.

- Resistência ao rasgo transversal - Norma Tappi T414. Om-88 - 71 amostras.

- Resistência ao rasgo longitudinal - Norma Tappi T414. Om-88 - 71 amostras.

- Resistência ao ar Gurley - Norma Tappi T460 om-96 - 489 amostras.

- Rigidez transversal - Norma Tappi T489 om-92- 413 amostras.

- Rigidez longitudinal - Norma Tappi T489 om-92- 413 amostras. 


\subsection{Microanálise dos papéis.}

\subsubsection{Microscopia eletrônica de varredura.}

Foi utilizado o equipamento Leica Modelo Stereoscan 440 para fotomicrografar a topografia do papel na direção $\mathrm{Z}$.

As amostras foram preparadas mergulhando tiras dos papéis cortados em nitrogênio líquido por aproximadamente 2 minutos. Após este tempo, retirou-se imediatamente as amostras congeladas e com o uso de uma pinça foram fraturadas uma a uma. As regiões fraturadas foram revestidas com ouro, necessário para aterramento do feixe de elétrons produzido pelo equipamento de análise. As amostras foram submetidas à câmara de alto vácuo do equipamento, focadas e registradas em imagens digitais.

\subsubsection{Microanálise química elementar.}

Durante a observação das imagens geradas pela microscopia eletrônica de varredura foi possível realizar a microanálise química elementar por raio $\mathrm{X}$, com o auxílio do equipamento Link/Oxford modelo eXLII, que apresenta picos semi-quantitativos dos elementos químicos, exceto hidrogênio, presentes 
numa determinada região da fibra. Esta análise pode detectar a presença dos elementos enxôfre, cálcio e alumínio que foram utilizados nos tratamentos, caso remanescentes nas fibras dos papéis formados. 


\section{DISCUSSÃO DOS RESULTADOS.}

\subsection{Características das folhas manuais e das suspensões de fibras.}

\subsubsection{Características das suspensões de fibras.}

As fibras em suspensão foram tratadas e mantidas a $\mathrm{pH}$ do teste por uma hora. Suas propriedades são apresentadas na Tabela 2 juntamente com a mostra original sem tratamento ( $\mathrm{pH}$ original 7,7$)$.

As fibras em meio alcalino tendem a diminuir o diâmetro do lúme, mantendo o mesmo diâmetro externo comparadas às fibras em meio ácido.

Como visto na revisão de literatura (Tabela 1, página 13), as camadas das fibras apresentam variação na composição de celulose e hemiceluloses conforme as espécies, sendo que o meio alcalino pode propiciar a transformação da celulose tipo I em celulose tipo II ( com menor grau de empacotamento), fato este que poderia explicar este fenômeno de inchamento interno da fibra.

Os principais componentes das fibras na polpa Kraft branqueada são celulose e hemiceluloses. Para a parede da fibra inchar os componentes químicos tem que apresentar grupos inonizáveis. 
De uma maneira geral, a polpa kraft branqueada apresenta grupos ácidos fracos. Na presença de água, a maioria dos grupos ácidos ficará na forma protonizada. Pode-se dizer que a parede celular incha como resultado da pressão osmótica entre a solução de íons livres dentro da parede e a água fora da parede. Na presença de solução de $\mathrm{NaOH}$, a maioria dos grupos ácidos ficará na forma ionizada (maior quantidade de íons livres dentro da parede, maior pressão osmótica resultando num maior inchamento). Na presença do meio ácido ocorre conversão dos grupos ácidos ionizados $(\mathrm{O} \mathrm{Na})$ para grupos ácidos protonizados $(\mathrm{OH})$ e portanto uma contração da parede celular.

O efeito de cátions no inchamento se dá pela sua valência, para uma dada quantidade de grupos ácidos, a quantidade de íons dentro da parede será menor quanto maior for sua valência. O grau de ionização será menor quanto maior a valência. Portanto o inchamento se deve a uma maior pressão osmótica dada ao maior número de íons livres com menor valência do cátion.

As características da tabela 2 refletem estes fenômenos onde se destaca que fibras em meio alcalino apresentam menor coeficiente de flexibilidade e maior fração parede, demonstrando uma tendência de menor acomodação entre fibras o que deve se refletir num maior volume específico aparente das folhas formadas. 
Tabela 2 - Propriedades das suspensões de fibras.

\begin{tabular}{|l|rr|rr|rr|c|}
\hline & \multicolumn{2}{|r|}{5,0} & \multicolumn{2}{|r|}{8,0} & \multicolumn{2}{|c|}{ Original } & \\
& Média & $\mathrm{cV} *$ & Média & $\mathrm{cV}$ & Média $\mathrm{cV}$ & Valor F \\
\hline Diâmetro do lúme, $\mu \mathrm{m}$ & 8,8 & 3,7 & 8,1 & 5,8 & 8,5 & 3,3 & $7,68^{*}$ \\
\hline Diâmetro da fibra, $\mu \mathrm{m}$ & 17,5 & 2,9 & 17,4 & 3,4 & 17,5 & 5,3 & $0,11^{\text {n.s. }}$ \\
\hline Espessura de parede, $\mu \mathrm{m}$ & 4,36 & 2,5 & 4,66 & 2,6 & 4,50 & 7,1 & $16,37^{* *}$ \\
\hline Coef. de flexibilidade, $\%$ & 49,7 & 1,2 & 46,0 & 2,5 & 47,5 & 0,3 & $41,23^{* *}$ \\
\hline Fração parede, \% & 50,3 & 1,2 & 54,0 & 2,1 & 52,1 & 6,1 & $41,23^{* *}$ \\
\hline
\end{tabular}

Legenda: $\quad \mathrm{CV}^{*}$ - Coeficiente de variação, \%

n.s. - Diferença não significativa

* Diferença significativa ao nível de $95 \%$ de probabilidade

** Diferença significativa ao nível de $99 \%$ de probabilidade

\subsubsection{Características ópticas das folhas manuais.}

As folhas manuais nas condições descritas anteriormente tem suas características apresentadas na tabela 3.

As características ópticas das folhas manuais apresentam valores superiores nas condições alcalinas. 
O maior coeficiente de espalhamento de luz, dependente da superfície exposta das fibras é resposta do menor contato fibra-fibra e consequentemente, interfaces fibra-ar mais extensas demonstrando a influência da menor compactação da estrutura, devido às fibras apresentarem menor coeficiente de flexibilidade, com menor acomodação entre si.

Isto ainda pode ser confirmado pelo maior valor de opacidade do papel formado em $\mathrm{pH} 8,0$ em relação ao papel formado em $\mathrm{pH} 5,0$. Tabela 3 - Propriedades ópticas das folhas manuais.

\begin{tabular}{|l|rr|rr|r|}
\hline & \multicolumn{2}{|r|}{5,0} & \multicolumn{2}{|r|}{8,0} & \\
& Média & $\mathrm{cV} *$ & Média & $\mathrm{cV}$ & Valor F \\
\hline C. E. L., $\mathrm{m}^{2} / \mathrm{Kg}$ & 43,6 & 0,4 & 46,5 & 0,7 & $178,8 * *$ \\
\hline Opacidade, \% & 85,0 & 0,1 & 86,9 & 0,9 & $19,1^{*}$ \\
\hline Alvura, \% (c/ filtro UV) & 81,3 & 0,6 & 84,4 & 0,2 & $127,1^{* *}$ \\
\hline
\end{tabular}

Legenda: $\quad \mathrm{CV}^{*}$ - Coeficiente de variação, \%

* Diferença significativa ao nível de $95 \%$ de probabilidade ** Diferença signifícativa ao nível de $99 \%$ de probabilidade

A menor alvura na colagem ácida é provocada provavelmente pela presença de resíduos ácidos que causam a hidrólise ácida dos componentes da polpa, causando amarelecimento, conforme descrito por PAISTE (1981). 


\subsubsection{Características físico-mecânicas das folhas manuais.}

As folhas formadas em laboratório tem suas características

físico-mecânicas apresentadas na tabela 4.

Tabela 4 - Propriedades físico-mecânicas das folhas manuais.

\begin{tabular}{|c|c|c|c|}
\hline $\mathrm{pH}$ & 5,0 & 8,0 & \\
\hline & Média $\mathrm{CV}^{*}$ & Média $\mathrm{CV}$ & Valor $\mathrm{F}$ \\
\hline Espessura, $\mu \mathrm{m}$ & $175 \quad 1,2$ & 184 & $46,0^{* *}$ \\
\hline Volume específico aparente, $\mathrm{cm}^{3} / \mathrm{g}$ & $2,05 \quad 0,9$ & 2,16 & $65,6 * *$ \\
\hline Alongamento, $\%$ & $3,2 \quad 18,8$ & 17,7 & $0,3^{\text {n.s. }}$ \\
\hline Resistência à tração, kN/m & 21,2 & $\overline{15,4}$ & $1,7^{\mathrm{n} \cdot \mathrm{s}}$ \\
\hline Resistência ao arrebentamento, $\mathrm{kPa}$ & \begin{tabular}{|ll}
253 & 19,8
\end{tabular} & 221 & $1,3^{\text {n.s. }}$ \\
\hline Resistência ao rasgo, $\mathrm{Mn}$ & 878 & 869 & $0,0^{\text {n.s. }}$ \\
\hline Resistência ao ar Gurley, s/100ml & 7,2 & 6,2 & $9,9 *$ \\
\hline Rigidez, gf.cm & 4,8 & 3,9 & $1,2^{\mathrm{n} . \mathrm{s}}$ \\
\hline
\end{tabular}

Legenda: $\quad \mathrm{CV}^{*}$ - Coeficiente de variação, \%

n.s. - Diferença não significativa

* Diferença significativa ao nível de $95 \%$ de probabilidade

** Diferença significativa ao nível de $99 \%$ de probabilidade 
A formação de folhas manuais se dá em condições especiais e diferentes dos papéis industriais onde se destaca a ausência de orientação das fibras no papel formado, bem como da prensagem à úmido, a qual é responsável pela consolidação da folha antes da secagem.

A espessura da folha mostrou-se influenciada pelo meio de formação, sendo maior para os papéis formados a pH 8,0 . O volume específico aparente, derivado deste $\mathrm{pH}$, mostrou-se maior, mas ressalta-se a ausência de prensagem, o que poderia resultar na conformação das fibras de forma mais pronunciada, com maior colapsamento e maior acomodação, porém este dado é importante pois mostra que mesmo após a secagem as folhas a $\mathrm{pH} 8,0$ apresentam maior volume que folhas a $\mathrm{pH} 5,0$.

A resistência à passagem de ar mostrou-se maior nos papéis a $\mathrm{pH} 5,0$, o que confirma a existência de maiores volumes vazios no papel.

Estas diferenciações nas características dos papéis podem ser explicadas observando-se que o coeficiente de flexibilidade das fibras: é menor em meio alcalino, ocasionando menor acomodação das fibras entre si.

Os testes de tração, alongamento, arrebentamento e rasgo não apresentaram diferenças significativas entre tratamentos o que demonstra que as ligações fibra-fibra não sofreram alterações significativas pela variação do meio de formação. 
A rigidez do papel não apresentou variação significativa, embora era esperado que as fibras tratadas em meio ácido, com maior coeficiente de flexibilidade, apresentassem menores valores. Isto pode ser um indicativo que durante a secagem, as fibras retornam a valores semelhantes de coeficiente de flexibilidade.

\subsection{Características do papel industrial.}

\subsubsection{Características ópticas.}

Suas características são apresentadas na tabela 5.

As características ópticas dos papéis industriais são dependentes do tipo e nível de carga empregado, sendo que no caso presente foi utilizado sempre o mesmo recurso fibroso.

A opacidade se mostra influenciada pelo meio de formação e pelo tipo de carga utilizado. O papel alcalino apresenta valores de opacidade elevada em relação ao ácido em função do carbonato de cálcio precipitado apresentar maior superfície específica que o caulim e provavelmente, pelo número de interfaces fibra-ar do papel como observado nas folhas manuais sem carga mineral. 
As cargas minerais promovem a opacidade notando-se uma resposta de interação no aumento de carga do papel alcalino. Todas as médias são diferentes ao nível de $95 \%$ de probabilidade pelo teste de Duncan.

A alvura do papel mostrou-se influenciada pelo tipo e teor de carga e $\mathrm{pH}$ de formação, isto se deve à maior alvura do carbonato de cálcio (98\% ISO) em relação ao caulim (84\% ISO). Existe interação negativa com o aumento de carga no papel ácido. Pelo teste de Duncan as médias a pH 5,0 com 15\% e $17 \%$ de carga apresentaram diferenças significativas ao nível de $95 \%$ de probabilidade. O mesmo não acontece com o papel alcalino.

Além da contribuição do tipo de carga, a diminuição do amarelecimento por hidrólise ácida nos papéis alcalinos também contribue para a menor perda da alvura original da polpa, $89 \%$ ISO. 


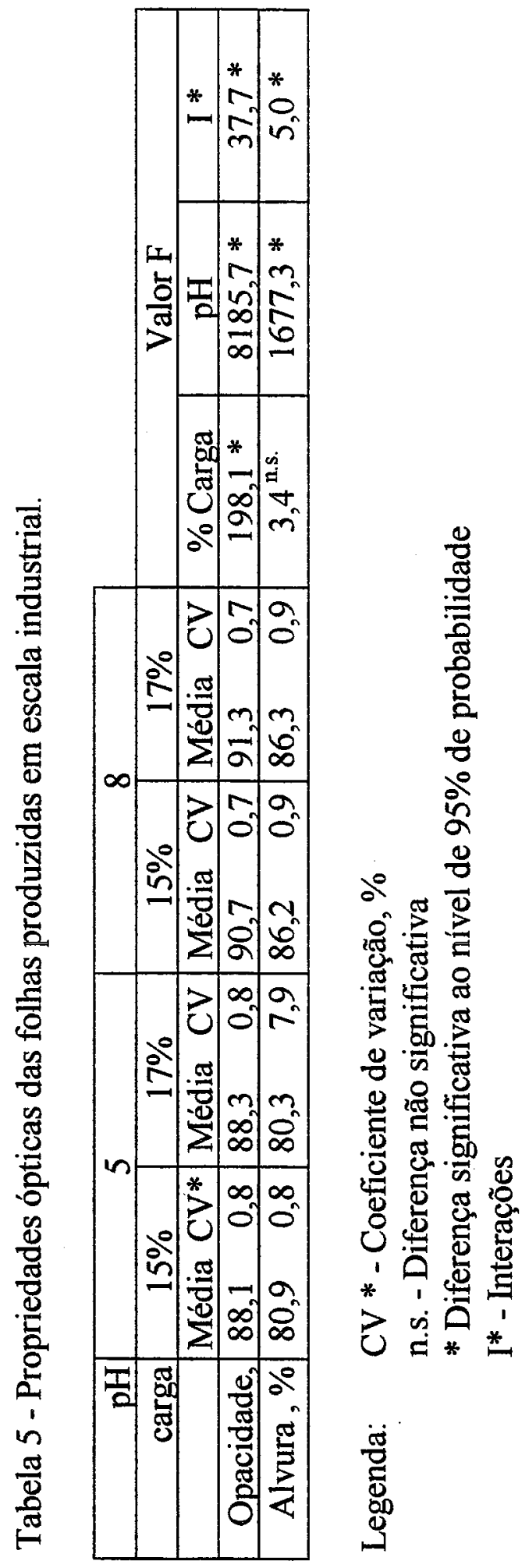




\subsubsection{Características físico-mecânicas.}

O papel industrial tem suas características físico-mecânicas apresentadas na tabela 6 . A espessura e consequentemente o volume específico aparente (a gramatura é controlada) respondem ao $\mathrm{pH}$ do meio, porém não responde à variação de carga de $15 \%$ a $17 \%$, mostrando que a variação de carga não age como fonte física de incremento ou diminuição de espessura para os limites de carga estudados e mesmas condições mecânicas de fabricação. O alongamento longitudinal apresenta-se influenciado pelo $\mathrm{pH}$ e teor de carga. $\mathrm{O}$ teste de Duncan não diferencia as médias a pH 5,0 com $15 \%$ e $17 \%$ de carga.

Observa-se que o papel alcalino apresenta menores valores de alongamento, provavelmente devido ao menor coeficiente de flexibilidade das fibras a úmido, resultando em deposição da fibra durante a formação de forma mais retilínea, com menores extensões acomodadas.

A análise estatística aponta interação, o aumento de carga de carbonato de cálcio decresce o valor de alongamento, provavelmente pela substituição de elementos anatômicos na forma retilínea por carga mineral, pois as fibras estão orientadas nesta mesma direção. Esta mesma alteração na condição ácida com caulim não é sentida, provavelmente pela maior acomodação das fibras entre si formando maiores sítios de fibras não distendidas. 


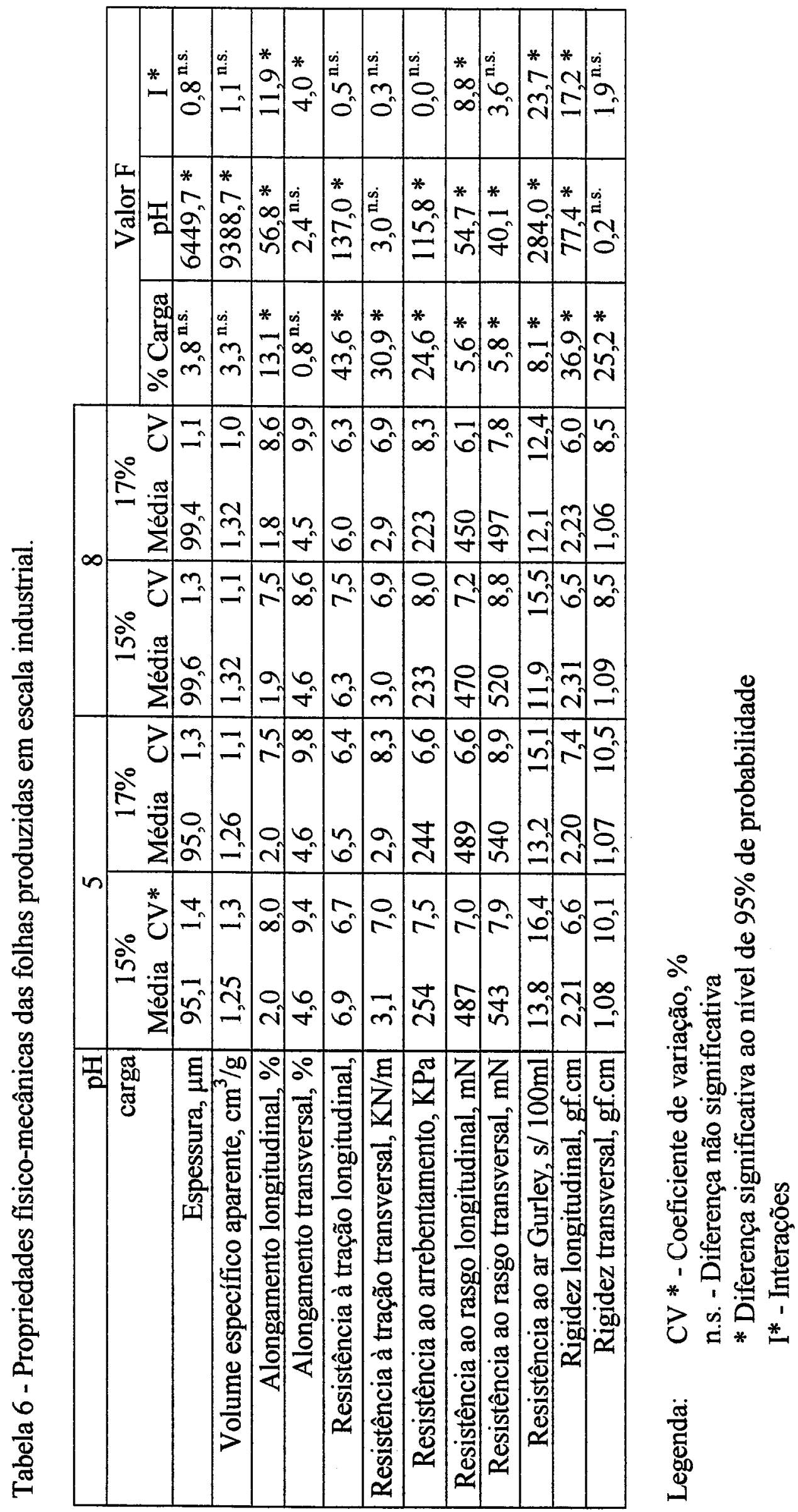


O alongamento transversal nos papéis industriais não apresentam-se influenciados pelo pH e carga, devido à orientação longitudinal das fibras, porém é apontada uma interação. O teste de Duncan diferencia o papel a pH 8,0 com $17 \%$ de carga dos demais ao nível de probabilidade de $95 \%$.

A resistência à tração longitudinal se comporta inversamente proporcional ao teor de carga e $\mathrm{pH}$ sendo que o teste de Duncan demonstra que todas as médias diferem entre si. Como esperado a substituição de fibra por carga diminui este parâmetro, sendo que papéis fabricados a $\mathrm{pH} 8,0$ apresentam menores valores em relação aos papéis fabricados a $\mathrm{pH} 5,0$ demonstrando a diminuição de contato fibra-fibra.

A resistência à tração transversal se mostra influenciada apenas pelo teor de carga.

O nível de carga crescente diminui os valores da resistência ao arrebentamento, bem como o aumento de $\mathrm{pH}$, sendo que os papéis a $\mathrm{pH} 8,0$ apresentam-se menos resistentes, o que reforça a discusssão do menor contato fibra-fibra dado seu maior volume específico aparente.

A resistência ao rasgo é dependente da densidade da folha, de forma que quanto mais denso o papel, maior a dificuldade de se puxar as fibras adjacentes à área de rasgo. As folhas formadas a $\mathrm{pH} 5,0$ apresentaram $1,26 \mathrm{~cm}^{3} / \mathrm{g}$ de volume específico aparente e as folhas formadas a $\mathrm{pH} 8,0$ apresentaram 
$1,32 \mathrm{~cm}^{3} / \mathrm{g}$. Calculando seu inverso, a densidade, as folhas formadas a $\mathrm{pH} 5,0$ apresentaram $0,79 \mathrm{~g} / \mathrm{cm}^{3}$ e as folhas formadas a $\mathrm{pH} 8,0$ apresentaram $0,76 \mathrm{~g} / \mathrm{cm}^{3}$.

Os resultados das análises de variâncias dos valores de rasgo transversal e longitudinal refletem esta afirmação, pois demonstram um decréscimo de valores para as folhas formadas a $\mathrm{pH} 8,0$ em relação às folhas à $\mathrm{pH}$ 5,0 e nas folhas formadas com $15 \%$ de carga em relação às folhas com $17 \%$ de carga.

$\mathrm{O}$ maior volume especifico aparente em folhas formadas a $\mathrm{pH}$ 8,0 reflete o maior volume de vazios, o que se confirma pelos menores valores de resistência ao ar, sendo que o aumento de carga do papel ácido diminui a resistência ao ar; já o papel alcalino, com o aumento de carga, fica levemente mais resistente ao ar possivelmente pelo enchimento dos espaços entre fibras com esta carga que apresenta $1,9 \mu \mathrm{m}$ de diâmetro, obstruindo espaços anteriormente vazios.

O caulim com $11 \mu \mathrm{m}$ de diâmetro separa ainda mais as fibras, facilitando a passagem do ar.

A rigidez longitudinal, mostra-se influenciada pelo teor de carga e $\mathrm{pH}$, sendo os papéis a pH 8,0 mais rígidos. O teste de Duncan apresenta os papéis fabricados a $\mathrm{pH} 5,0$ com $15 \%$ e $17 \%$ de carga com médias que não diferem entre si. Isto confirma a expectativa de que o papel fabricado a $\mathrm{pH} 8,0$ é 
mais rígido devido ao menor coeficiente de flexibilidade de seus elementos fibrosos, sendo que o incremento de $15 \%$ para $17 \%$ de carga de carbonato de cálcio diminui estes valores, talvez pelo seu menor tamanho, ocupando o espaço de interfaces fibra-fibra, diminuindo a coesão entre elas.

A rigidez transversal, sofre também a influência da orientação longitudinal das fibras do papel industrial, apresentando valores muito menores que os obtidos no sentido longitudinal e sendo influenciada apenas pelo nível de carga. O aumento de carga diminui a rigidez transversal por diminuir o contato fibra-fibra, deixando a resistência ao esforço axial entre ligações diminuida.

\subsection{Características microanalíticas dos papéis.}

\subsubsection{Fotomicrografias dos papéis.}

As fotomicrografias da fratura na direção $Z$ dos papéis estão apresentadas a seguir pelas Figuras 1 a 8 .

São apresentadas as regiões de fratura das fibras no papel, mostrando fibras individuais (Figuras 1 a 6 ) dos papéis a pH 5,0 e pH 8,0, nas 
folhas manuais e industriais, e nas fibras sem tratamento não sendo possível perceber variações entre elas.

Nas folhas manuais (Figuras 7 e 8) com pH 5,0 e pH 8,0, no aumento de 500 vezes, são visualizados os perfís da estrutura fibrosa, onde é percebido um menor nível de acomodação das fibras no papel com $\mathrm{pH} 8,0$, porém não é possível afirmar quais as dimensões ou características das fibras são responsáveis por esse efeito. 
FIGURA 1 - FOTOMICROGRAFIA DE FIBRAS TRATADAS EM pH 5,0

(FOLHAS MANUAIS)

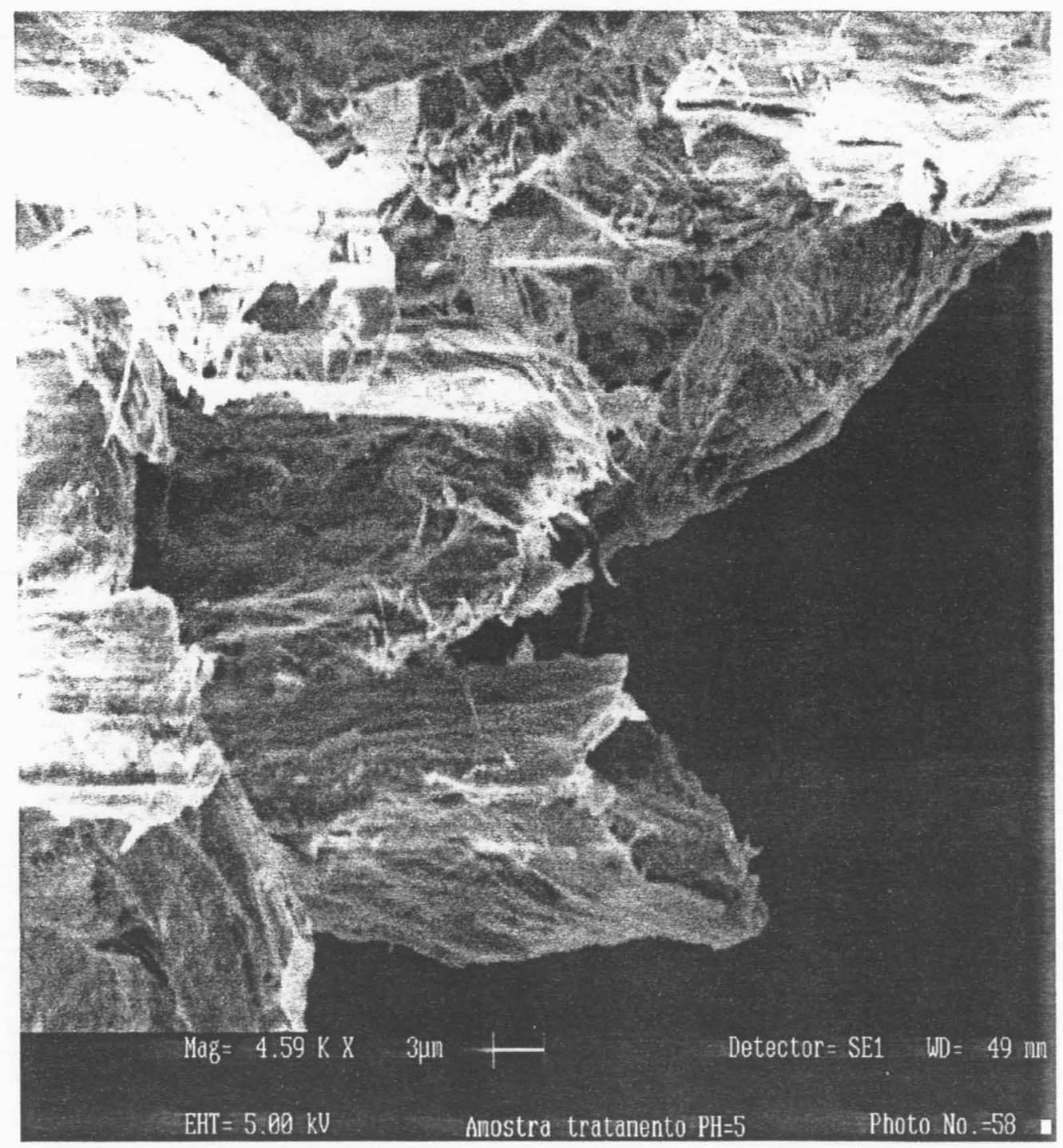


FIGURA 2 - FOTOMICROGRAFIA DE FIBRAS TRATADAS EM pH 8,0

$$
\text { (FOLHAS MANUAIS) }
$$

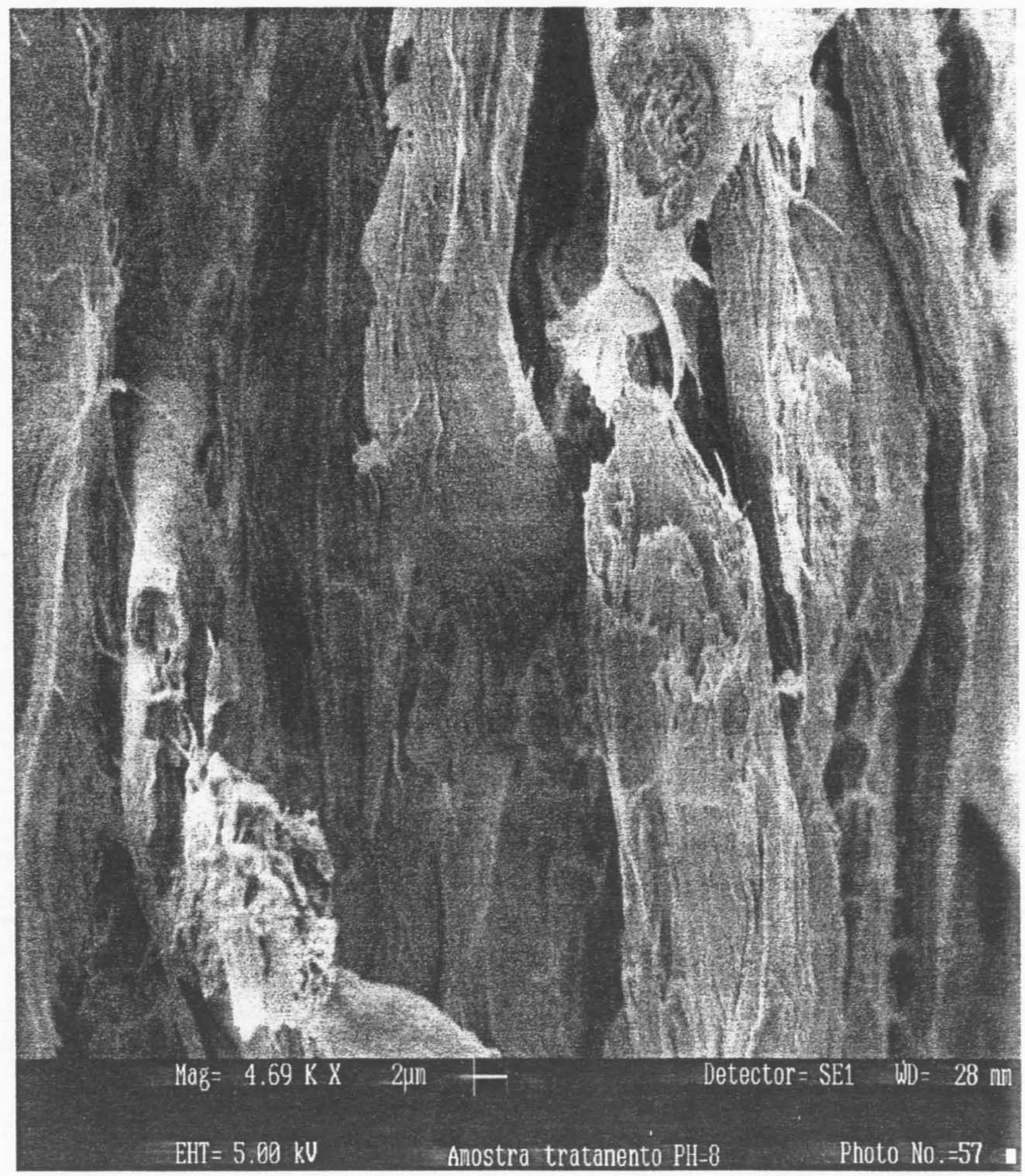


FIGURA 3 - FOTOMICROGRAFIA DE FIBRAS TRATADAS EM pH 5,0 (PAPEL INDUSTRIAL)

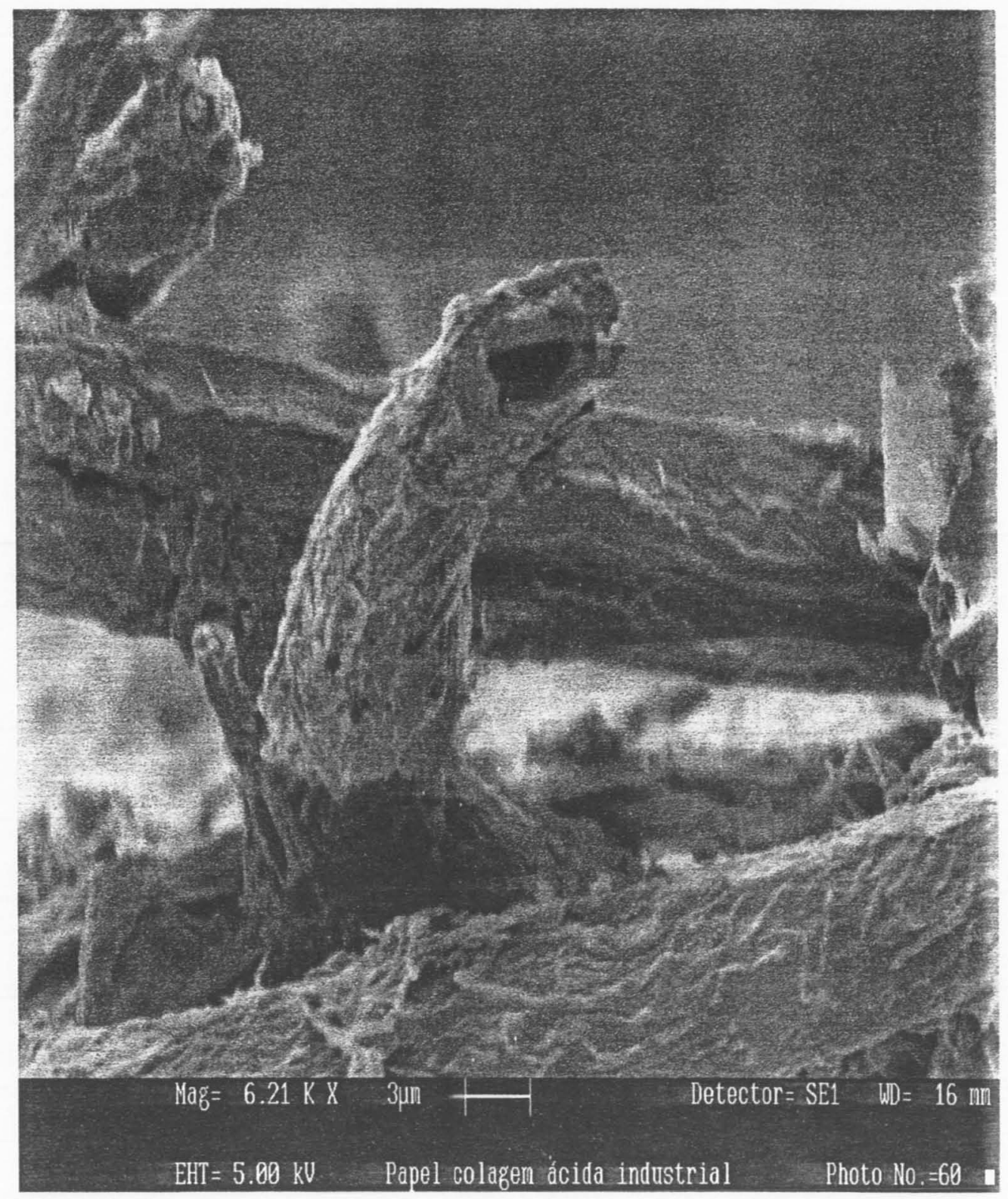


FIGURA 4 - FOTOMICROGRAFIA DE FIBRAS TRATADAS EM pH 8,0

\author{
(PAPEL INDUSTRIAL)
}

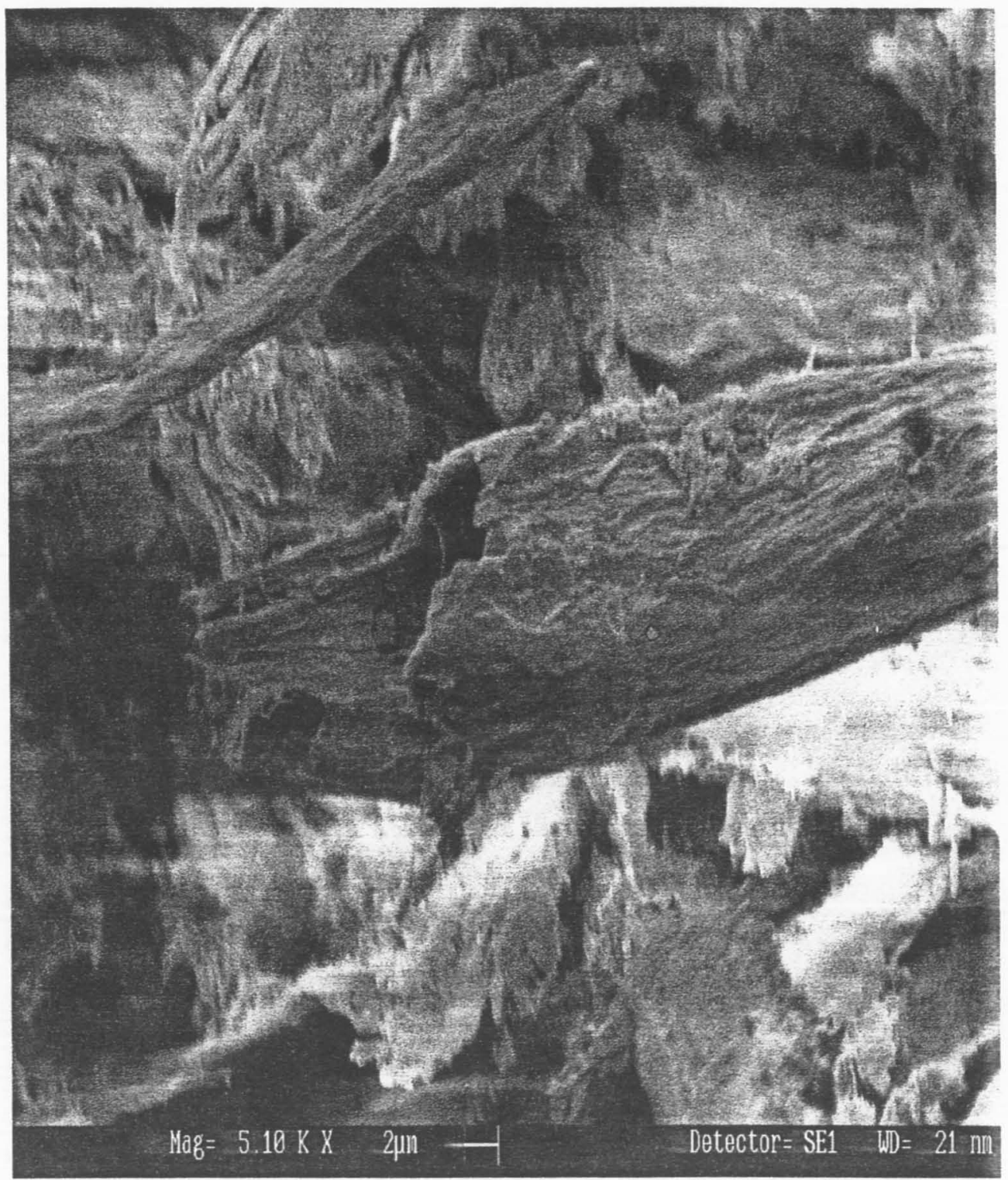

EII $=5.00 \mathrm{kV}$ Papd odagendcaimaindand

Protolo 61 


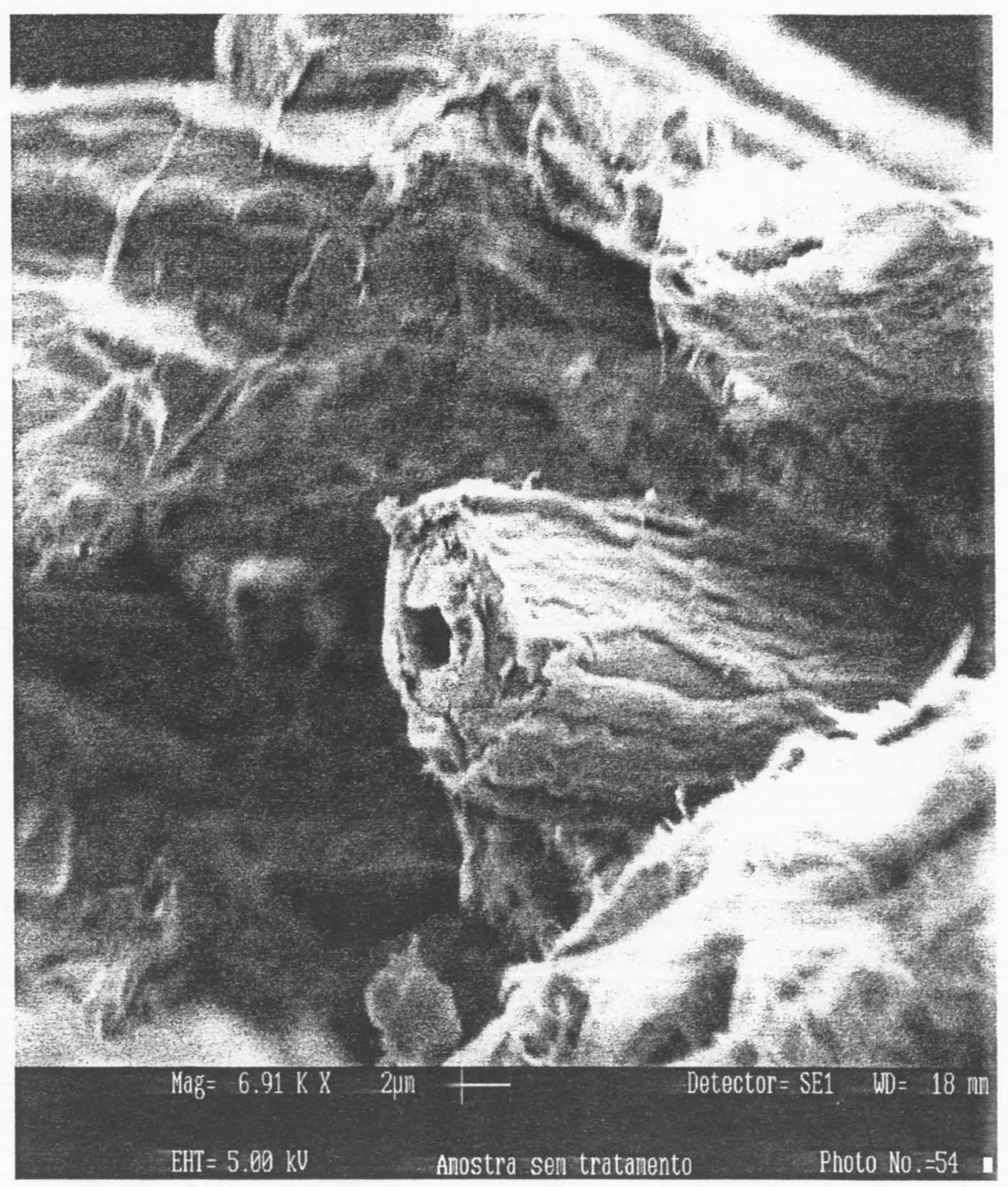




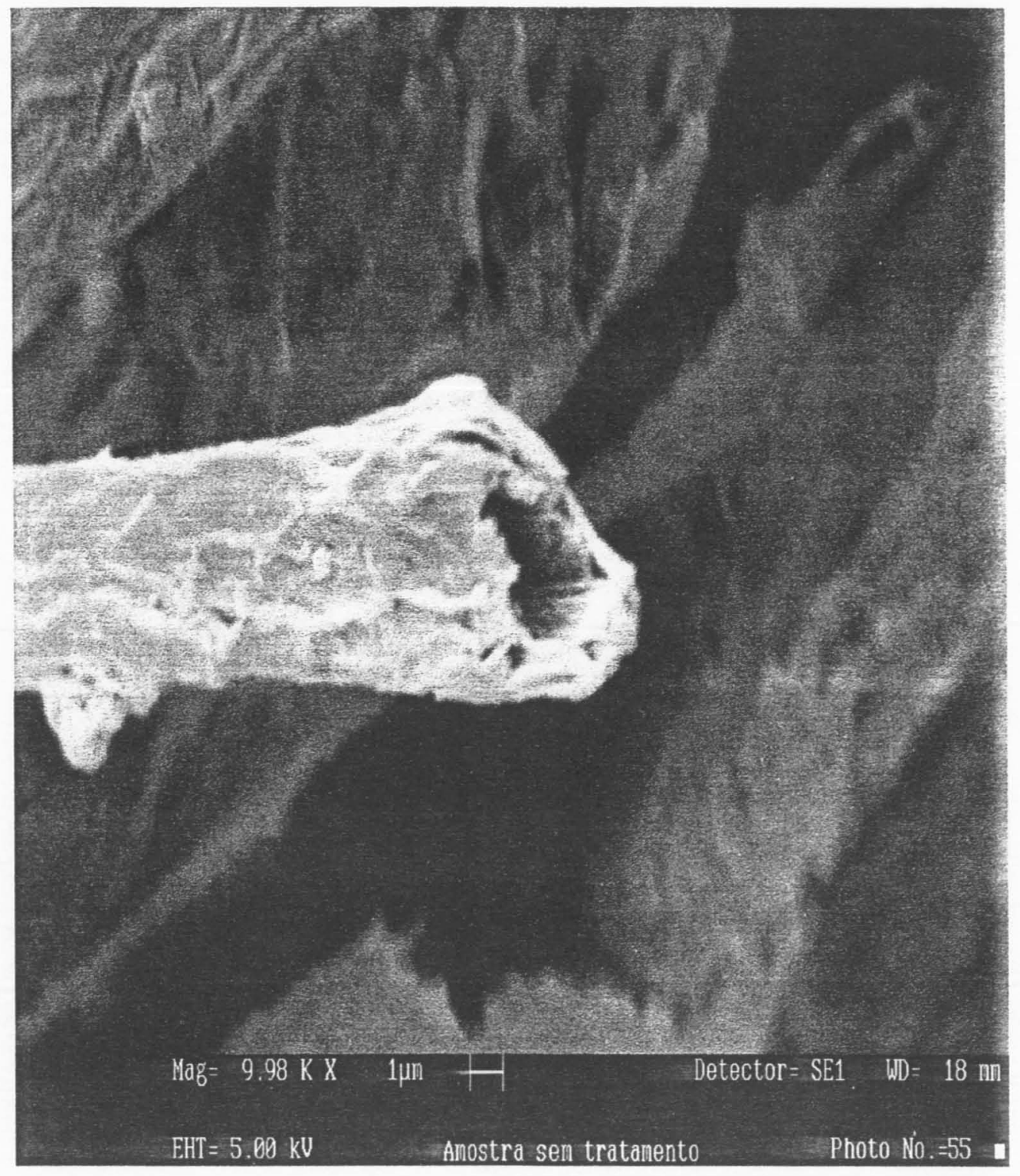


FIGURA 7 - FOTOMICROGRAFIA DO PAPEL FABRICADO A pH 5,0

(FOLHAS MANUAIS)

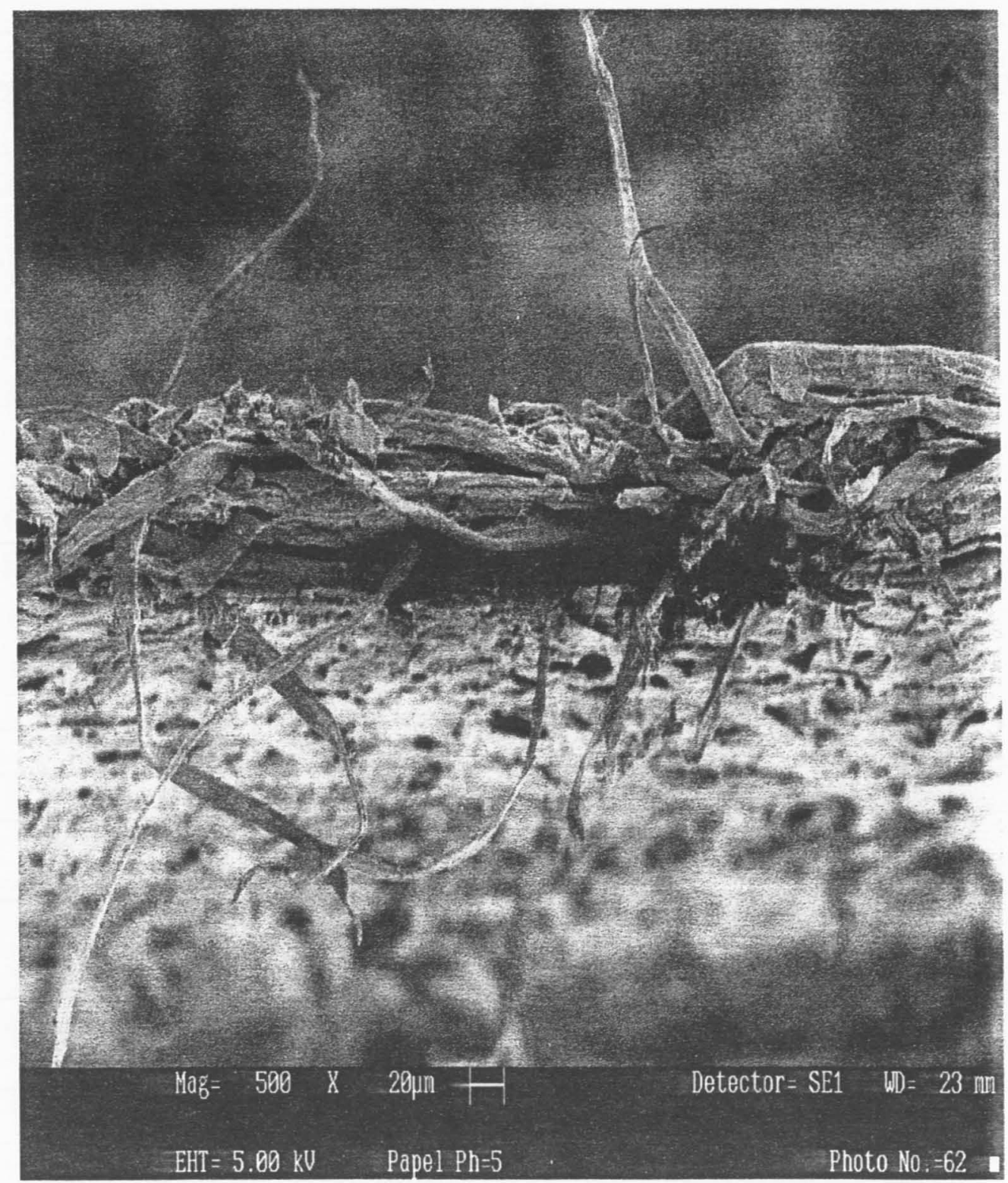


FIGURA 8 - FOTOMICROGRAFIA DO PAPEL FABRICADO A pH 8,0

(FOLHAS MANUAIS)

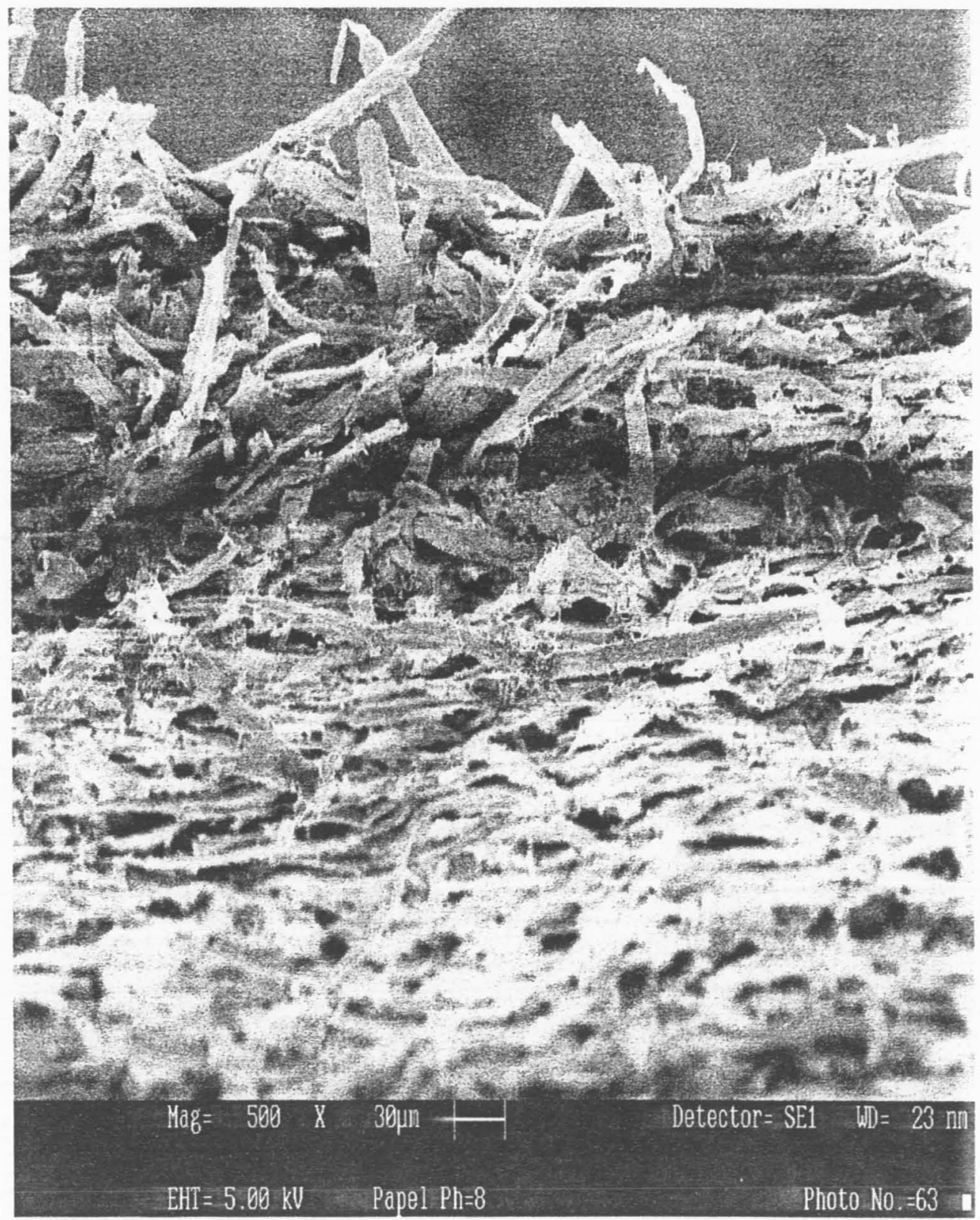




\subsubsection{Composição química elementar das fibras no papel.}

Os perfis dos papéis foram analisados quimicamente por raio $\mathrm{X}$, apresentando os elementos mais frequentes, cujos histogramas de cada análise podem ser observados figuras 9 a 13.

O elemento ouro, observado em todas as análises, deve ser ignorado como componente do papel pois o mesmo foi agregado à amostra com a finalidade de aterrar os elétrons do feixe do equipamento de análise. O elemento hidrogênio não é detectável pelo equipamento.

É observado em todas as análises a presença de carbono, oxigênio e silício (este em menor intensidade, menor que $0,5 \%$ ), sendo que nas amostras de folhas manuais com $\mathrm{pH} 5,0$ e fibras originais (sem tratamento) detectou-se uma pequena presença de alumínio (entre 0,5 e $1 \%$ ), porém este não foi detectado nos papéis industriais.

Esta análise é semi-quantitativa sendo que o foco de raio $\mathrm{X}$ foi sempre focado na região da fratura da fibra, onde não se observou nenhuma influência de elementos químicos relacionados com o $\mathrm{pH}$ de fabricação de amostras ou características dos papéis. 
FIGURA 9 - MICROANÁLISE DA AMOSTRA ORIGINAL

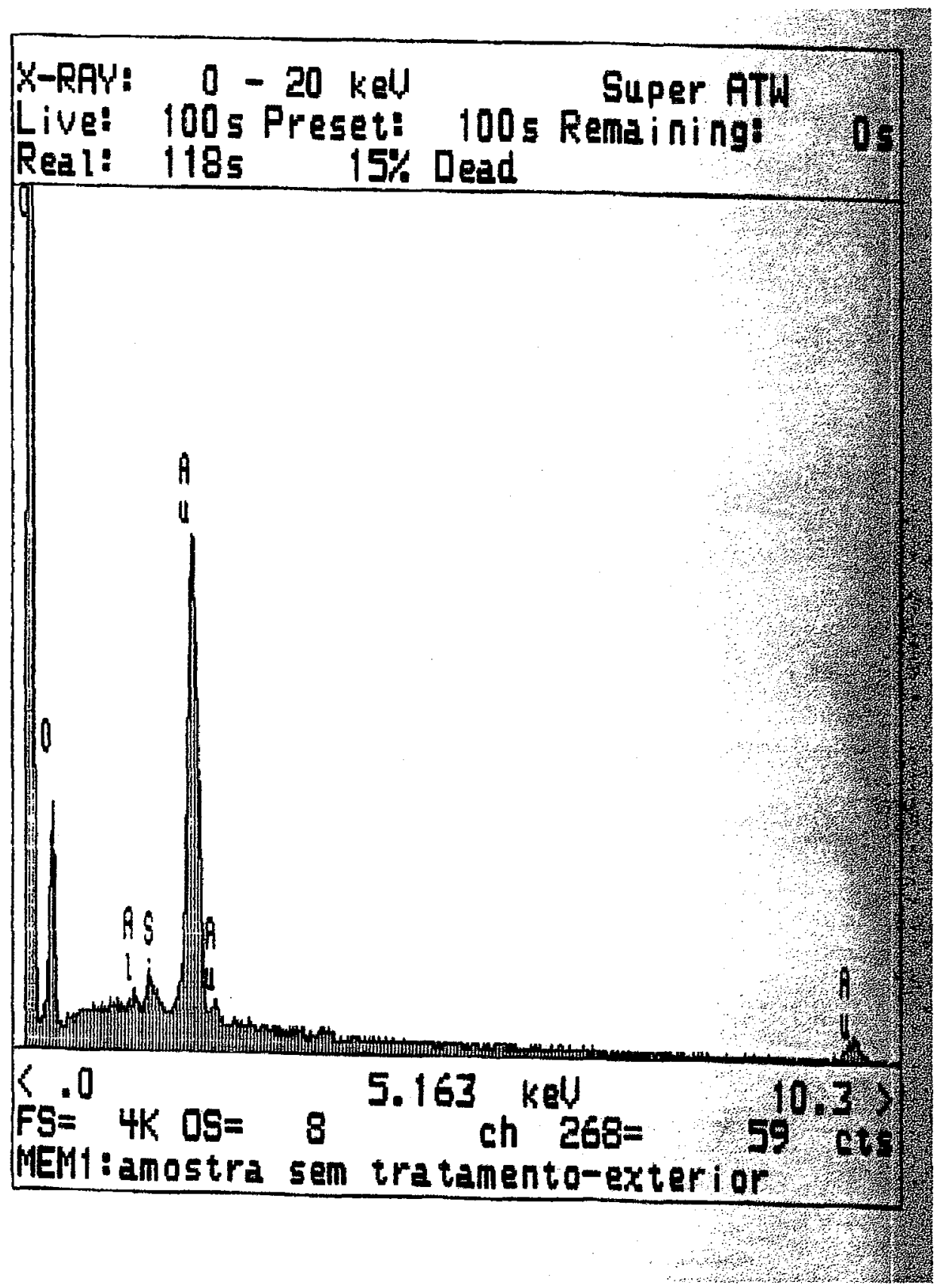


FIGURA 10 - MICROANÁLISE DA FOLHA TRATADA EM pH 5,0 (FOLHAS MANUAIS)

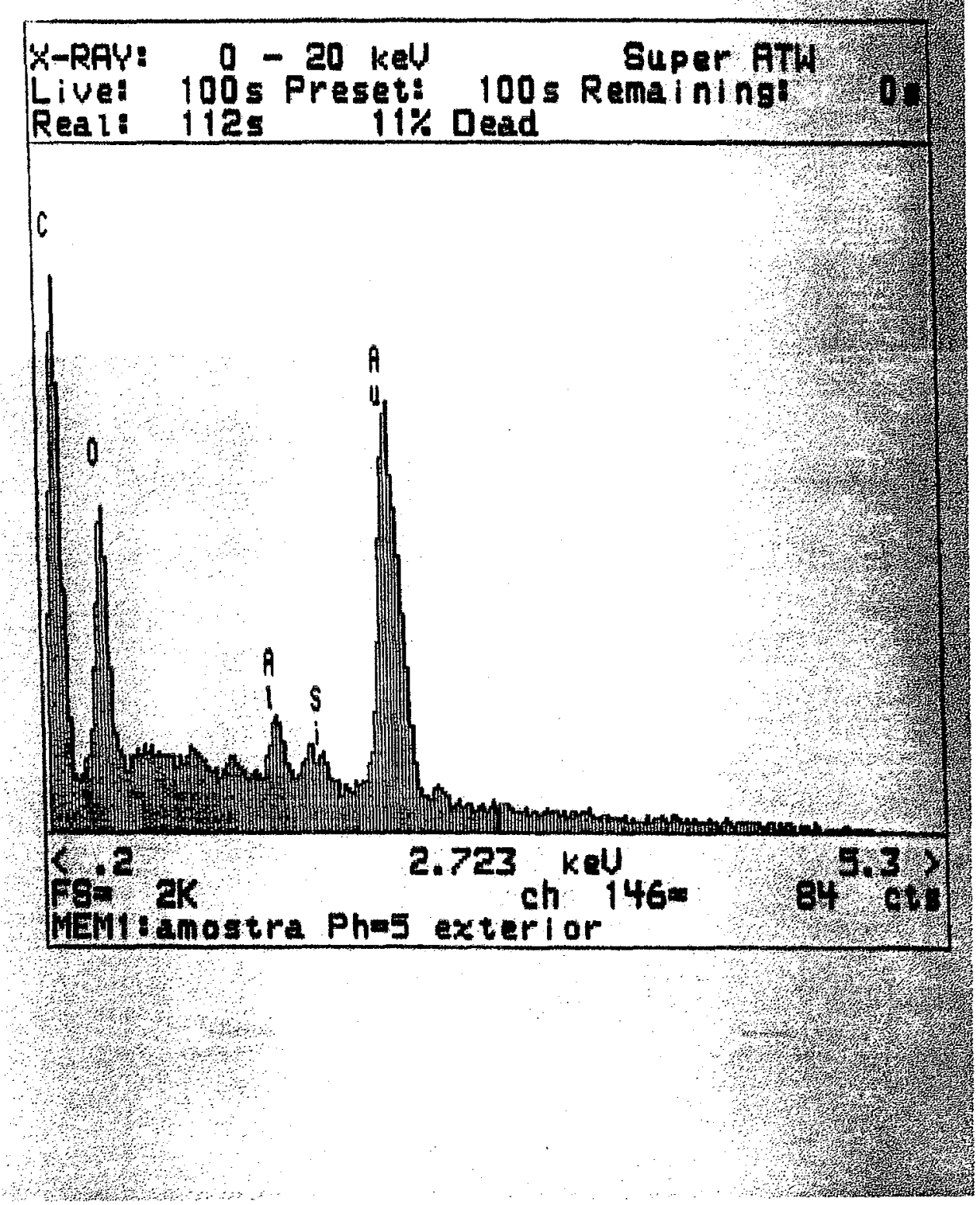


FIGURA 11 - MICROANÁLISE DA FOLHA TRATADA EM pH 8,0

(FOLHAS MANUAIS)

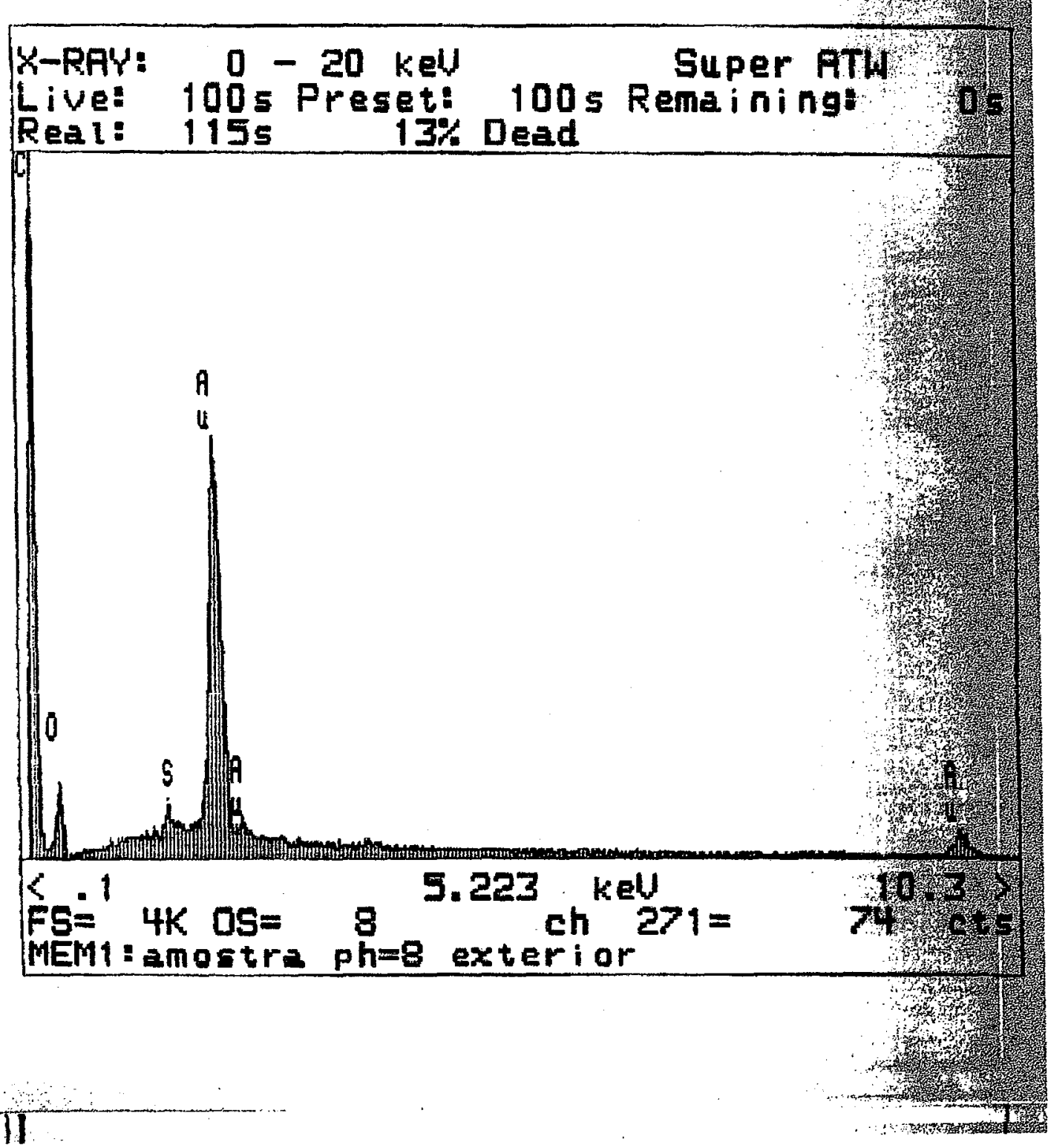


FIGURA 12 - MICROANÁLISE DA FOLHA TRATADA EM pH 5,0 (PAPEL INDUSTRIAL)

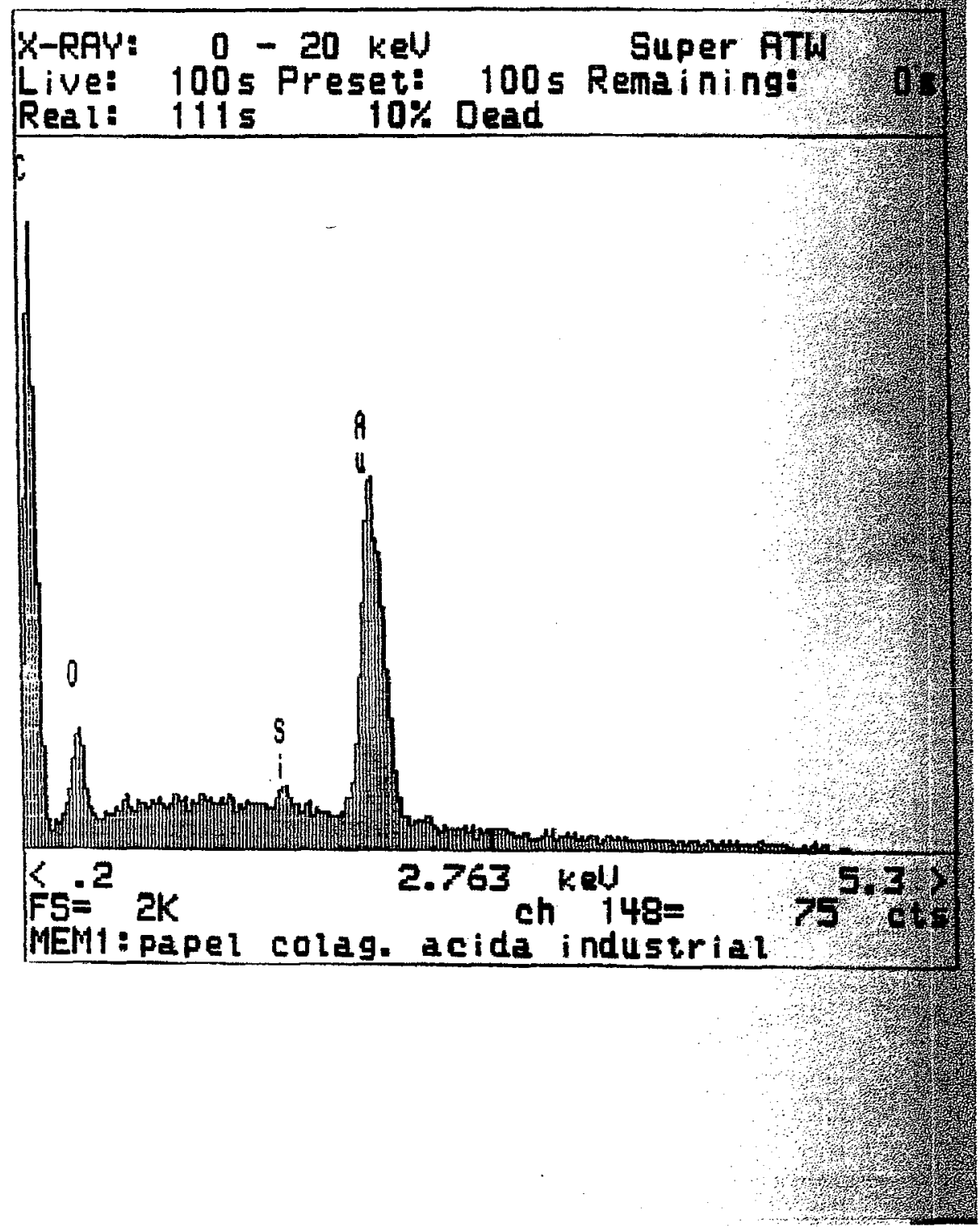


FIGURA 13 - MICROANÁLISE DA FOLHA TRATADA EM pH 8,0 (PAPEL INDUSTRIAL)

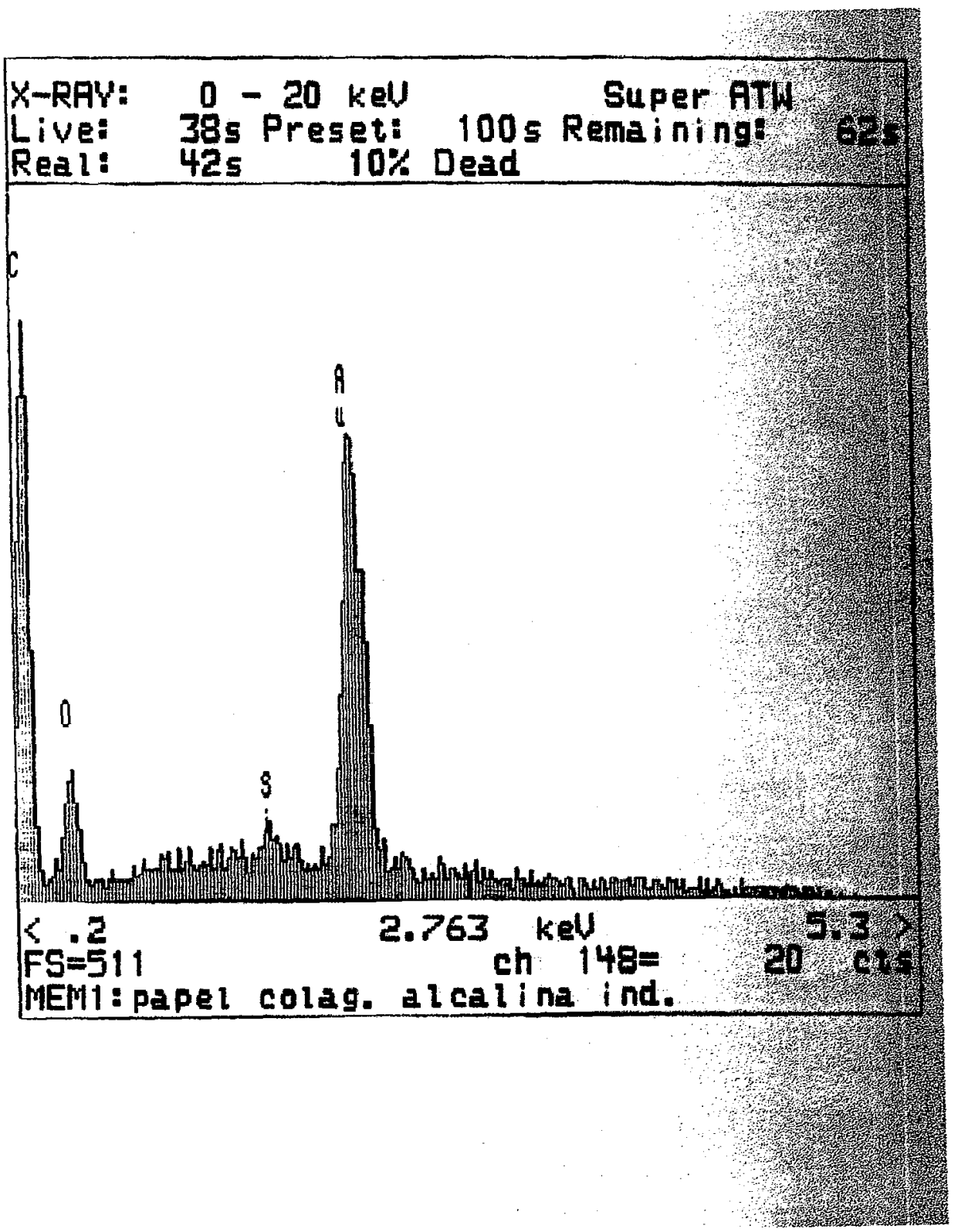




\subsection{Influência do $\mathrm{pH}$ de formação nas características do papel.}

No item 5.1. foram analisadas as características das folhas manuais com controle de $\mathrm{pH}$ da suspensão, porém sem carga mineral, e no item 5.2. as características de papéis industriais fabricados a $\mathrm{pH}$ ácido $(5,0)$ e a pH alcalino $(8,0)$ com duas classes de carga mineral $15 \%$ (14 a 16\%) e $17 \%(16,1$ a $18 \%)$ cada um deles.

Confrontando os resultados pode-se observar que as características ópticas, opacidade e alvura, são influenciadas pelo $\mathrm{pH}$ de formação, sendo a opacidade menor no papel a pH 5,0 resultante de uma maior acomodação das fibras e consequentemente maior extensão de contato fibra-fibra.

A alvura menor nos papéis ácidos são resultantes da ação dos radicais ácidos que promovem a hidrólise dos compostos da polpa.

Estes fenômenos estão ligados ao pH de formação sendo que o incremento de carga promove ainda mais a opacidade.

Os parâmetros físicos espessura e volume específico aparente mostram-se influenciados somente pelo $\mathrm{pH}$ sendo que o teor de carga nos níveis estudados $(15 \%$ e $17 \%)$ não representam uma contribuição fisica para estas modificações, demonstrando que as modificações a nível de fibra são as responsáveis por este fenômeno. 
As caracteristicas fisico-mecânicas das folhas de laboratório não apresentam diferenciações devido à não orientação das fibras. A resistência ao ar, dependente apenas dos volumes vazios, demonstra a maior acomodação das fibras nos papéis a $\mathrm{pH} 5,0$, resultante de seu maior coeficiente de flexibilidade a úmido.

As características físico-mecânicas das folhas de papéis industriais, confirmam o valor de resistência ao ar maior para papéis a $\mathrm{pH} 5,0$, sendo que o incremento de carga é responsável pela diminuição desta resistência pelo maior tamanho das partículas de caulim $(11 \mu \mathrm{m})$ que é próximo à largura das fibras à úmido.

O papel fabricado a $\mathrm{pH} 8,0$ apresenta menor resistência ao ar, mas com o incremento de carbonato de cálcio esta resistência aumenta, pelo seu tamanho de partícula de $1,9 \mu \mathrm{m}$ que ocupa os volumes vazios da estrutura do papel.

A rigidez do papel, quando este se apresenta com orientação das fibras (papéis industriais), mostra-se levemente superior nos papéis fabricados a $\mathrm{pH} 8,0$, resultante da menor flexibilidade das fibras tratadas neste $\mathrm{pH}$. 


\section{CONCLUSÕES.}

O meio de formação influência as características do papel produzido com polpa sulfato branqueada de Eucalyptus spp.

O meio ácido promovido pelo sulfato de alumínio e o meio alcalino pelo carbonato de cálcio, resultando em hidróxido de cálcio, são responsáveis pela diferenciação anatômica das fibras. Esta diferenciação se deve à modificações químicas de suas camadas estruturais e, consequentemente, são afastadas as hipóteses de um dos reagentes estar incorporado às fibras, estes apenas devem provocar sua modificação. Isto se baseia nos resultados da microanálise química por raio $\mathrm{X}$.

O aumento de hidroxilas livres migradas do meio para as fibras, também pode ser um fator de diferenciação, entumecendo-as e causando a modificação estrutural nos componentes da polpa. Esta é uma nova área de estudos a ser explorada. 
As fibras tratadas em meio ácido apresentam maior diâmetro do lúme que as tratadas em meio alcalino, sempre com o diâmetro externo inalterado em condições úmidas.

Estes fenômenos propiciam a formação de papéis mais densos quando as fibras são tratadas em meio ácido, com maior flexibilidade das fibras favorecendo o colapsamento a úmido por prensagem, provocando maior acomodação das fibras entre si comparado ao papel com fibras tratadas em meio alcalino.

O maior volume específico aparente do papel alcalino comparado ao papel ácido, promove maior coeficiente de espalhamento de luz e opacidade.

Estas características são devidas às maiores extensões de contato fibra-ar, o que pode ser incrementado com cargas minerais com maiores superfícies específicas.

A diminuição das resistências físico-mecânicas no papel alcalino são devidas ao menor número de contatos fibra-fibra, com maior número de fibras menos acomodadas. Uma ressalva se faz à rigidez longitudinal, que tende a ser maior devido ao menor coeficiente de flexibilidade, detectável nos papéis industriais com orientação de fibras na formação. 
A contribuição das cargas minerais variam com as características das mesmas. O aumento de carga utilizando caulim diminui a alvura e aumenta a opacidade, enquanto com o carbonato de cálcio tende a aumentar a alvura e opacidade. De maneira geral, o aumento de cargas minerais diminuem as resistências mecânicas.

A resistência ao ar diminui com o incremento de carga em papéis ácidos utilizando caulim, pois seu tamanho de partícula é próximo à largura das fibras a úmido aumentando o número de volumes vazios na folha de papel.

$\mathrm{O}$ incremento de carga em papéis alcalinos aumenta a resistência ao ar, pois o carbonato de cálcio ocupa os volumes vazios formados pelas fibras em função de seu menor tamanho em relação às fibras. 


\section{REFERÊNCIAS BIBLIOGRÁFICAS}

CLARK, J. D'A. Pulp technology. New York: Miller Fredman, 1982. 752p.

D'ALMEIDA, M. L. O. Celulose e papel: Tecnologia de fabricação da pasta celulósica. São Paulo: Escola SENAI "Theobaldo de Nigris", 1988. Volume 1 Capítulo III, p. 45-106: Composição química de materiais lignocelulósicos.

FAIRCHILD, G. H. Increasing the filler content of PCC-filled alkaline papers. Tappi Journal, p. 85-90, 1992.

FENGEL, V. Wood: Chemistry ultrastructure reaction. Berlim Walter Gruyter, $1984.626 \mathrm{p}$.

GALLAY, W. Cellulose-water relationships. Pulp and paper science and technology, vol. I - Pulp. New York: McGraw-Hill Book Co., 1962. 436p. 
GERTEISER, N.; LAUFMAN M. Effects of natural ground $\mathrm{CaCO}_{3}$ on woodfree papermaking process and paper quality. Surrey: PIRA, 1987, seção IV:trabalho 15.

GLL, R. A. The performance of precipitate calcium carbonate fillers in fine quality printing and writing papers. In: MATERIAL INTERACTION RELEVANT TO PULP, PAPER AND WOOD INDUSTRIES. Bethlehem: Tappi Press, 1990. p. 325-341.

HAGEMEYER, R.W.; WELCH L.J. Natural calcium carbonate for alkaline paper. Tappi, n.64, p. 97-100, maio 1981.

KAMITI, M.; VAN DE VEN T. G. M. Kinetics of deposition of calcium carbonate particules onto pulp fibres. Journal of Pulp and Paper Science, $n$. 29, p. 199-205, jul. 1994.

LYNE, M. B.; ASPLER, J. S. Wetting and sorption of water by paper under dynamic conditions. Tappi Journal n.65, p.98-101, dez. 1982. 
MARTON, J. Practical aspects of alkaline sizing: alkil ketene dimer in mill furnishes. Tappi Journal, p. 187-191, ago. 1991.

McGINNIS, G.D.; SHAFIZADEH, F. Cellulose and hemicellulose. In: Casey, J.P., ed. Pulp and paper chemistry and chemical technology. New York: John Wiley and Sons, 1980. Volume 1 Capítulo 1, p. 1-38.

PAISTE, D.P. Considerations for alkaline papermaking. Tappi, n. 64, p. 97-99, abr. 1981.

PASSARETI, J. D. High opacity fillers: A new PCC morphology and its properties in wood free and wood containing paper. In: PAPERMAKERS CONFERENCE. Atlanta: Tappi Press, 1991, p.293-298.

RIEBELING, H. U. Encolantes, parámetros de influencia y limites de los encolantes sintéticos en la massa. ACOTEPAC, p. 15-27, fev. 1990.

RYDHOM, S.A. Pulping Process. New York: Interscience Publishers, 1965. 1296p. 
SANDERSON, E. The effects of alkaline paper on the offset lithographic printing processes. In: NEUTRAL/ALKALINE PAPERMAKING. Tappi Short Courses Notes. Atlanta: Tappi Press, 1990. p. 45-48.

SCLAWAY, A.C.; WILLIAMS J.C. Alkalinity - the key to paper "permanence". Tappi, n.64, p. 49-50, maio 1981.

WATHERHOUSE, J. F. \& BARRET T. D. The aging characteristics of European handmade papers: 1400-1800. Tappi Journal, p. 207-212, out. 1991. 
APÊNDICE 


\section{CARACTERIZAÇÃo DA POLPA UTILIZADA}

A polpa sulfato branqueada de eucalipto utilizada é composta de 70\% Eucalyptus grandis, 20\% Eucalyptus saligna e 10\% Eucalyptus urophylla.

O processo de branqueamento ocorreu em 4 estágios:

$$
\text { (O-C/D-Eop-D) }
$$

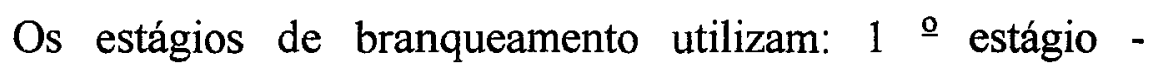
oxigênio, $2^{\circ}$ estágio - cloro e dioxido de cloro, $3^{\circ}$ estágio - hidróxido de sódio e peróxido de hidrogênio e $4^{\circ}$ estágio - dióxido de cloro.

As características de viscosidade e alvura são apresentadas na tabela a seguir, juntamente com o teor de pentosanas determinado pelo método Tappi T233 cm-95.

As características morfológicas analisadas foram o teor de finos, comprimento médio ponderado (em peso) das fibras, Coarseness (ou número de decigrex) e número de fibras por grama de polpa. Estas determinações foram possíveis com uso do equipamento Kajaani FS-100.

O teor de finos é a quantidade de elementos anatômicos menores que $0,076 \mathrm{~mm}$ (equivalente ao material que passaria por uma tela de 200 
mesh de mesa formadora de máquina de papel, em tese) valor este arbitrado segundo norma TAPPI T261 cm-94 sendo expresso em percentual de elementos de comprimento entre 0,000 e $0,076 \mathrm{~mm}$ em relação ao número total de elementos anatômicos analisados.

$$
\text { O comprimento médio ponderado em } \mathrm{mm} \text { é dado pelo }
$$

equipamento.

Através de cálculos utilizando o peso da amostra seca, número total de fibras e percentual de finos, obteremos o Coarseness ou número de decigrex em $\mathrm{mg} / 100 \mathrm{~m}$, indicando maior ou menor robustez da fibra; é determinado ainda o número de fibras por grama.

\begin{tabular}{|l|l|}
\hline \multicolumn{2}{|c|}{ Características da polpa. } \\
\hline Viscosidade, cp & 17 \\
\hline Alvura, \% ISO & 89 \\
\hline Teor de pentosanas, \% & 18,0 \\
\hline Comprimento médio ponderado, mm & 0,86 \\
\hline Teor de finos (<0,0076mm), \% & 2,96 \\
\hline "Coarseness", mg/100m & 7,2 \\
\hline Número de fibras por grama, milhões & 11,8 \\
\hline
\end{tabular}

